\title{
ANÁLISIS CRÍTICO DEL TÍTULO SEXTO SOBRE COMBATE A LA CORRUPGIÓN Y BUEN GOBIERNO DE LA CONSTITUCIÓN POLÍTICA DE LA GIUDAD DE MÉXICO*
}

\author{
Irma Eréndira SANDOVAL BALLESTEROS**
}

\begin{abstract}
SUMARIO: I. Introducción. II. Vicios procedimentales. III. Los siete yerros del combate a la corrupción. IV. Simulación constitucionaly leyes secundarias. V. Conclusión: Cuarto Poder Ciudadano. VI. Anexo: texto alternativo de artículos 60, 61, $62,63,64$ y 66 .
\end{abstract}

\section{INTRODUCCIÓN}

El presente artículo analiza desde un enfoque crítico el Titulo Sexto de la Constitución Política de la Ciudad de México en materia del combate a la Corrupción. Explica las razones que llevaron a anular la gran oportunidad que se vislumbraba para combatir la corrupción de manera decidida en la capital del país y expone los fallos y aberraciones principales que se pueden encontrar en esta importante sección. Detalla asimismo en qué consistía la esencia del planteamiento del Cuarto Poder Ciudadano Anticorrupción y las razones por las que tal iniciativa fue desechada por la Asamblea Constituyente. Concluye planteando que en materia de combate a la corrupción la primera Constitución Política de la Ciudad de México representa una oportunidad perdida y la mayor parte del contenido dedicado al "Buen Gobierno" se caracteriza por lugares comunes, declaraciones y repeticiones de normas federales que no han tenido absolutamente ningún impacto en el grave problema de la corrupción y la mala administración.

* Artículo recibido el 16 de octubre de 2017 y aceptado para su publicación el 13 de noviembre de 2017.

** Investigadora de tiempo completo del Instituto de Investigaciones Sociales y directora del Laboratorio de Documentación y Análisis de La Corrupción y la Transparencia de la UNAM. Diputada constituyente de la Giudad de México y Secretaria de la Mesa Directiva de la Comisión de Buen Gobierno, Combate a la Corrupción y Régimen de Responsabilidades de los Servidores Públicos, de la Asamblea Constituyente.

Boletín Mexicano de Derecho Comparado, nueva serie, año XLX, núm. 152, mayo-agosto de 2018, pp. 869-912.

Esta obra está bajo una Licencia Creative Commons Atribución-NoComercial-SinDerivar 4.0 Internacional, IIJ-UNAM. 
El texto se divide en cuatro secciones. Parte de un recuento de las fallas procedimentales y yerros organizativos que caracterizaron los trabajos de la comisión legislativa que presentó el dictamen inicial. En la segunda parte se describen los siete criterios de análisis jurídico que explican el gran fracaso del combate a la corrupción en la Constitución. Entre otros aspectos destacan: a) una concepción neoliberal de la austeridad; $b$ ) la prescripción de los delitos de corrupción; $c$ ) la inconstitucionalidad de las asociaciones público-privadas; $d$ ) la nula rendición de cuentas para actores provenientes del sector privado; e) una porosa definición del concepto de conflictos de interés; $f$ ) la inoperatividad del servicio profesional de carrera, y $g$ ) la falta de indicadores de desempeño, seguimiento y evaluación en la Constitución.

La tercera parte abunda en el análisis de las leyes secundarias y las debilidades del sistema anticorrupción local resultante para la Ciudad de México. Aquí se argumentará que se debe procurar un sistema que busque una plena ciudadanización y democratización de los órganos de control e impartición de justicia y no como parece estar ocurriendo: uno al servicio del clientelismo político o de la captura en la designación de los servidores públicos a cargo del mismo sistema. Por último, la cuarta y última parte concluye con la propuesta de constitucionalizar un "Cuarto Poder Ciudadano". Se ofrecerán las razones que sustentan su viabilidad, se ofrecerá el texto constitucional alternativo que se propuso tanto al interior de la comisión legislativa de Combate a la Corrupción como en la discusión más amplia sostenida en el pleno de la Asamblea Constituyente. Se argumentará que estos mínimos pero importantes ajustes al texto constitucional finalmente aprobado, pudieron haber transformado de fondo el título Sexto de la Constitución Política de la Ciudad de México.

\section{VICIOS PROGEDIMENTALES}

La Comisión de Buen Gobierno, Combate a la Corrupción y Régimen de Responsabilidades de los Servidores Públicos de la Asamblea Constituyente estuvo presidida por Armado Ríos Piter, un político designado desde el Senado. Lamentablemente lo que mal empieza mal acaba, y durante el proceso de dictaminación de las modificaciones que proponían los diputados constituyentes, se desarrollaron prácticas inapropiadas y abiertamente autoritarias por parte de ese senador entonces perteneciente al PRD,

Esta obra está bajo una Licencia Creative Commons

Atribución-NoComercial-SinDerivar 4.0 Internacional, IIJ-UNAM.

Boletín Mexicano de Derecho Comparado, núm. 152, pp. 869-912. 
quien a la postre resultó ser un perfecto representante del transfuguismo político. ${ }^{1}$ La Comisión de Buen Gobierno también contó con la participación de perredistas de nuevo cuño como Tobyanne Ledesma y Nelly Juárez, quienes de forma disciplinada no cuestionaron, en lo más mínimo, las indicaciones recibidas por su presidente. Pero esta comisión también contó con el aval de conspicuos políticos de más largo vuelo como Jesús Ortega Martínez; el exgobernador de Guanajuato, Juan Carlos Romero Hicks; el exgobernador del Estado de México, Cesar Camacho Quiroz; Estela Damián, exdiputada del partido "Movimiento Ciudadano", fundado por el exgobernador de Veracruz, Dante Delgado; la expresidenta del PAN, Cecilia Romero Castillo; la exdiputada también panista, Teresa Gómez Mont, y el exlegislador en tiempos del presidente Díaz Ordaz, Augusto Gómez Villanueva, entre otros.

Como era de esperarse la comisión de "Buen Gobierno", en sus trabajos, invirtió más en retórica que en propuestas comprometidas, firmes y decididas para el combate a la corrupción. Las diversas iniciativas legislativas presentadas por la ciudadanía y los expertos proyectaban desde el principio poner un alto a prácticas y casos vergonzosos de corrupción como el protagonizado por el exgobernador de Veracruz,

1 Ríos Piter es un político expriísta, expanista, exfoxista, exzedillista y hoy experredista que llegó de forma antidemocrática a la Asamblea Constituyente valiéndose de su cargo y amparado por el Partido de la Revolución Democrática. Se ha sostenido que este político guerrerense logró su escaño de senador gracias a la masiva votación en Guerrero a favor de Andrés Manuel López Obrador en las elecciones federales de 2012. Está también documentado que en su transfuguismo irrefrenable traicionó el mandato izquierdista del pueblo de Guerrero al avalar el "Pacto por México" y respaldar el incremento de uno de los impuestos más regresivos para las clases trabajadoras: el IVA en la frontera. Votó también por incrementos mensuales a las gasolinas, los famosos "gasolinazos". Este político se ausentó también como senador en la sesión del 10 de marzo de 2015 y ello le permitió a Eduardo Medina Mora, procurador del ex presidente Felipe Calderón alcanzar la mayoría calificada para convertirse en ministro de la Suprema Corte de Justicia. De manera disparatada, el político guerrerense se autoproclamó "candidato independiente" a la Presidencia de la República y con éstas y otras acciones ha pasado a la historia como uno de los representantes populares que menor "sapiencia y probidad" dejaron en la cuestionada Asamblea Constituyente. Navarro Méndez, J. I., "Patología del transfuguismo político: Grandes males, pero ¿buenos remedios? (A propósito de la regulación del estatuto de los diputados «no adscritos» contenida en la reforma del Reglamento de la Asamblea de Extremadura, de 29 de marzo de 1999)", Revista de las Cortes Generales, núm. 49, 2000, pp. 7-55. Cfr. Sandoval Ballesteros, I. E., "Guerrero en la Constituyente de la CDMX", El Sur de Acapulco, 20 de febrero de 2017, disponible en: http://suracapulco.mx/9/guerrero-en-la-constituyente-de-la-cdmx.

Esta obra está bajo una Licencia Creative Commons Atribución-NoComercial-SinDerivar 4.0 Internacional, IIJ-UNAM. Boletín Mexicano de Derecho Comparado, núm. 152, pp. 869-912. 
Javier Duarte, ${ }^{2}$ o los innumerables episodios de endeudamiento público de tantos políticos mediante documentación falsa. ${ }^{3}$ La propuesta anticorrupción central de la fracción parlamentaria de Morena, el llamado "Cuarto Poder Ciudadano", fue desde el principio desechada sin mayor trámite.

Desafortunadamente las prácticas inapropiadas y el abierto autoritarismo se manifestaron en innumerables errores de procedimiento, negligencia e incluso mala fe por parte de muchos de los miembros arriba señalados que no respetaron el reglamento interno de la Asamblea Constituyente. Lo anterior acarreó un pobre análisis de cada uno de los artículos y permitió la eliminación, modificación o adición del proyecto de Constitución sin mayor reflexión.

La comisión de "Buen Gobierno" no se tomó el tiempo necesario para estudiar con seriedad las iniciativas ciudadanas o las provenientes de los otros diputados constituyentes que llegaron a su seno, a pesar de que en su mayoría dichos documentos se encontraban extraordinariamente fundados y motivados. Jamás hubo una exposición pormenorizada y mucho menos una discusión y votación en el pleno de la comisión de cada una de las iniciativas como hubiera sido recomendable. El supuesto "análisis" y procesamiento de las iniciativas finalmente plasmado en el dictamen fue producto de un trabajo de evidente pobreza legislativa y estrictamente burocrático de parte del equipo de asesores del presidente de la Comisión. Los documentos de trabajo nunca fueron presentados o analizados por los diputados de la comisión de manera sistemática. Con esta simulación, se excluyó completa-

2 Ángel, Arturo, "Del nuevo PRI a la corrupción de Javier Duarte", The New York Times, 8 de mayo de 2017, disponible en: https://wrww.nytimes.com/es/2017/05/08/delnuevo-pri-a-la-corrupcion-de-javier-duarte. Peschard, Jacqueline, "Javier Duarte: icono de la corrupción", El Universal, 17 de abril de 2017, disponible en: http://wwweluniversal.com.mx/ entrada-de-opinion/articulo/jacqueline-peschard/nacion/2017/04/17/javier-duarte-icono-de-la.

3 Para mayores y nuevos ejemplos confróntese el más reciente informe de la ASF que ha señalado mediante 604 auditorías, 624 de cumplimiento financiero y 38 auditorías de desempeño y dos estudios adicionales que los episodios de endeudamiento público mediante documentación falsa sigue in crescendo. Tan sólo en 2017 la ASF emitió 1587 recomendaciones, 41 promociones de comprobación fiscal, 238 solicitudes de aclaraciones, 798 promociones de responsabilidad administrativa y 796 pliegos de observaciones. Véase Cámara de Diputados, Agencia de Noticias, 2017, nota núm. 7242, disponible en: http:// bit.ly/2iozHDT; Auditoría Superior de la Federación, Consideraciones para la Labor Legislativa. Entrega de Informes Individuales, octubre de 2017, disponible en: http://informe.asf.gob.mx/Documentos/InformeGeneral/Consideraciones.pdf.

Esta obra está bajo una Licencia Creative Commons

Atribución-NoComercial-SinDerivar 4.0 Internacional, IIJ-UNAM.

Boletín Mexicano de Derecho Comparado, núm. 152, pp. 869-912. 
mente la voz ciudadana de las deliberaciones y se desperdició una enorme oportunidad para enriquecer el debate parlamentario. ${ }^{4}$ Los ciudadanos, e incluso los mismos diputados, fueron reducidos a ser simples espectadores.

Asimismo, el 29 de noviembre de 2016, el presidente de la Comisión publicó de manera unilateral la propuesta de predictamen en la Gaceta Parlamentaria de la Asamblea Constituyente sin el aval ni la firma de ninguno de los integrantes de la Mesa Directiva de la Comisión. ${ }^{5}$ Posteriormente se maniobró para que utilizando un espurio "Acuerdo de la Comisión con relación a la adopción de reglas para la discusión del Proyecto de Dictamen" (sic.) se impusiera el 2 de diciembre de $2016^{6}$ una "votación en lo general" del predictamen desde el propio inicio de la sesión que estaba convocada para la discusión. Se obligó así a cada diputado a presentar por escrito sus "reservas" al texto ya "aprobado". La discusión de "reservas" en lugar del debate directo sobre el contenido de cada artículo restringió de manera artificial e ilegal el procedimiento parlamentario. El Reglamento Interno de la Asamblea Constituyente no contempló reservas porque en el artículo 40 de ese documento quedó claramente establecido que la discusión y votación para aprobar la Constitución se haría artículo por artículo. ${ }^{7}$

Este procedimiento violó también la obligación que tenían los diputados de permitir la libre discusión tal como lo establecía el artículo 6 o. fracción 9, del Reglamento Para el Gobierno Interno de la Asamblea Constituyente de la Ciudad de México que estipulaba lo siguiente: "Serán obligaciones de los diputados y las diputadas: 9. Permitir la libre discusión y decisión parlamentaria en las sesiones, así como en las reuniones...”.

4 "Rechaza Morena Proyecto sobre Combate a la Corrupción en Asamblea Constituyente", Reforma, 30 de noviembre de 2016, disponible en: http://wrere.reforma.com/aplicacioneslibre/articulo/default.aspx?id=995375 \&md5=81927f2d88ad949912b90ee5aa71319a \& $t a=0$ dfdbac11765226904c16cb9ad1b2efe.

5 La Política Online, "Morena denuncia un «madruguete» de Ríos Piter en la Asamblea Constituyente", 30 de noviembre de 2016, disponible en: http://wwrelapoliticaonline.com. $m x /$ nota/95091.

6 Véase "Comunicación de la diputada Irma Eréndira Sandoval Ballesteros", Gaceta Parlamentaria, 23 de enero de 1916, disponible en: http://gaceta.diputados.gob.mx/ACCM/ GP/20170125-I.pdf.

7 Véase "Intervención de Diputada Constituyente Irma Eréndira Sandoval como Secretaria de la Mesa Directiva de la Comisión de Buen Gobierno, Combate a la Corupción y Régimen de Responsabilidades de los Servidores Públicos", sesión del 4 de diciembre de 2016, disponible en: https://wrwr.facebook.com/IrmaErendiraSandoval/videos/ 1315996641764948 . 
El "voto en lo general" desde el principio no tenía otro fin que el de acartonar y limitar la discusión parlamentaria, ya que de todas formas este "voto en general" tuvo que repetirse de manera artificial al final de la discusión como aval al texto finalmente integrado a partir de las "reservas" de los diputados miembros de la comisión. El formato más democrático y plural hubiera sido la discusión libre de artículo por artículo como lo establecía el reglamento Interior de la Asamblea Constituyente.

Estos atropellos procedimentales resultaron particularmente preocupantes tomando en cuenta que la Mesa Directiva de la Asamblea Constituyente, forzada por las circunstancias, ya había ampliado el plazo para la discusión y aprobación de los dictámenes de las comisiones hasta el 10 de diciembre de 2016 y este procedimiento acartonado y antidemocrático se impuso el 2 de diciembre de 2017. ${ }^{8}$ En lugar de trabajar con calma, seriedad y rigor, tomando en cuenta plenamente las iniciativas de los ciudadanos y las opiniones de los diputados sobre cada artículo, el senador Armando Ríos, abusando de su posición en la Mesa Directiva, adelantó el procedimiento por medio de un clásico "madruguete" para imponer un texto elaborado de "al vapor" de manera apurada, descuidada y autoritaria.

\section{LOS SIETE YERROS DEL COMBATE A LA CORRUPCIÓN}

Como reseñamos en la primera sección, el senador designado y presidente impuesto de esta comisión, al final de cuentas, privilegió la velocidad por encima de la calidad y la profundidad de la deliberación en la comisión.

La comisión rechazó docenas de iniciativas ciudadanas y de diputados constituyentes sin argumentación jurídica, constitucional o analítica alguna. En particular se desechó la propuesta de constituir un "Cuarto Poder Ciudadano" aduciendo una supuesta y desde luego inexistente "inconstitucionalidad" que supuestamente violaría la recién aprobada Ley General del Sistema Nacional Anticorrupción.

Sin embargo, para llegar a esta infundada conclusión nunca se ofreció análisis de constitucionalidad alguno, sino que simplemente se adujó una serie de afirmaciones inconexas sin rigor jurídico que terminaron de-

8 Véase "Comunicación de la diputada Irma Eréndira Sandoval Ballesteros", Gaceta Parlamentaria, miércoles 25 de enero de 2017, disponible en: http://gaceta.diputados.gob.mx/ ACCM/GP/20170125-I.pdf.

Esta obra está bajo una Licencia Creative Commons

Atribución-NoComercial-SinDerivar 4.0 Internacional, IIJ-UNAM.

Boletín Mexicano de Derecho Comparado, núm. 152, pp. 869-912. 
mostrando un total desconocimiento del sistema normativo mexicano. En defensa del cuarto poder anticorrupción, siempre se sostuvo que habría que remitirse al artículo 40 de la Constitución mexicana que a la letra dice: "Es voluntad del pueblo mexicano constituirse en una República representativa, democrática, laica y federal, compuesta por Estados libres y soberanos en todo lo concerniente a su régimen interior, y por la Ciudad de México, unidos en una federación establecida según los principios de esta ley fundamental". ${ }^{9}$

El artículo es muy claro: el pueblo mexicano y cada uno de sus estados, así como la Ciudad de México, son libres y soberanos, tienen la facultad de decidir sobre su régimen político interior así como dotarse de las instituciones políticas que consideren las más convenientes para una convivencia plena es derecho de cada uno de los mexicanos. En este sentido, crear un sistema anticorrupción de carácter autónomo y ciudadanizado va acorde a la Constitución porque es una decisión soberana, sin olvidar que el artículo 113 de la carta magna también establece que: "El Sistema Nacional Anticorrupción es la instancia de coordinación entre las autoridades de todos los órdenes de gobierno competentes en la prevención, detección y sanción de responsabilidades administrativas y hechos de corrupción, así como en la fiscalización y control de recursos públicos". ${ }^{10}$

Es decir, los gobiernos locales al tener autonomía política pueden darse a sí mismos el sistema anticorrupción que mejor se ajuste a sus necesidades; que a su vez tiene la obligación de coordinarse con el sistema federal. Lo último es básico, porque el mandato constitucional se refiere a la coordinación y no a la subordinación. Coordinarse se refiere a la acción de conectar medios, esfuerzos, etcétera, para una acción común entre las distintas instancias de gobierno de un país.

La Suprema Corte de la Nación comparte esta misma perspectiva y así lo refleja en la Jurisprudencia 207030 que, entre otros elementos, señala que:

El artículo 133 de la Constitución Politica de los Estados Unidos Mexicanos no establece ninguna relación de jerarquía entre las legislaciones federal y local, sino que en el caso

9 Constitución Política de los Estados Unidos Mexicanos, 1917, artículo 40, numeral 4.

10 Ibidem, artículo 113, párr. 1. 
de una aparente contradicción entre las legislaciones mencionadas, ésta se debe resolver atendiendo a qué órgano es competente para expedir esa ley de acuerdo con el sistema de competencia que la norma fundamental establece en su artículo 124. Esta interpretación se refuerza con los artículos 16 y 103 de la propia Constitución: ${ }^{11}$

En consecuencia la carta magna de la Ciudad de México abdicó de su legítima facultad para establecer un sistema anticorrupción. Ello además era completamente acorde con lo que prescribe la Constitución Política de los Estados Unidos Mexicanos. Tampoco es posible olvidar que, el artículo 1o. de la misma Constitución ordena de acuerdo al principio pro homine que siempre se deben interpretar las normas conforme lo más favorable a las personas. En consecuencia, un Sistema Anticorrupción debería ampliar la gama de derechos de la población (incluso sobrepasando lo establecido en la ley general) y su disfrute. Por lo anterior, el haber constituido un sistema anticorrupción diferente del SNA correspondiente a la Federación era perfectamente viable y necesario para asegurar los derechos de todos los habitantes de la Ciudad de México. Aún más, ello hubiera sido la forma más segura de honrar la Constitución federal y los tratados de derechos humanos internacionales. Asimismo, la Suprema Corte ha señalado que el examen de regularidad de una norma no se hace a partir de su adecuación a alguna legislación secundaria.

Es evidente que el presidente designado de esa Comisión no supo realizar un análisis de constitucionalidad, pues argumentó, mostrando una clara ignorancia de la norma, que "la propuesta era inconstitucional por violentar una ley secundaria" (sic.). Fue evidente desde un principio que esa consideración chocaba frontalmente con la forma en que la propia Suprema Corte de Justicia ha señalado que debe realizarse un análisis de constitucionalidad:

REGULARIDAD GONSTITUGIONAL DE UNA NORMA ORDINARIA. NO ES VÁLIDO REALIZAR EL EXAMEN RESPECTIVO A PARTIR DE SU ADEGUAGIÓN A ALGUNA LEGISLACIÓN SEGUNDARIA.

El análisis sobre la regularidad constitucional de una norma se efectúa atendiendo al contenido legal impugnado y su compulsa con los preceptos

11 Suprema Corte de Justicia de la Nación, Semanario fudicial de la Federación, t. VII, marzo de 1991, jurisprudencia (constitucional) 207030, disponible en: http://bit.ly/2yPa5WO.

Esta obra está bajo una Licencia Creative Commons

Atribución-NoComercial-SinDerivar 4.0 Internacional, IIJ-UNAM.

Boletín Mexicano de Derecho Comparado, núm. 152, pp. 869-912. 
de la Constitución Política de los Estados Unidos Mexicanos, así como con los derechos fundamentales que ésta y los tratados internacionales de los que México es parte tutelan. De ahí que no es válido evaluar la constitucionalidad de una norma ordinaria a partir de su adecuación a alguna legislación secundaria, porque ello condicionaría la constitucionalidad de un ordenamiento legal a la calificación de los factores asumidos por el legislador ordinario para emitir sus leyes secundarias en detrimento del principio de supremacía constitucional, lo que es inaceptable en nuestro sistema jurídico.

Amparo directo en revisión 5816/2014. 2 de diciembre de 2015. Unanimidad de cuatro votos de los Ministros Arturo Zaldívar Lelo de Larrea, José Ramón Cossío Díaz, Jorge Mario Pardo Rebolledo y Alfredo Gutiérrez Ortiz Mena. Ponente: Arturo Zaldívar Lelo de Larrea. Secretario: Saúl Armando Patiño Lara. ${ }^{12}$

\section{Austeridad neoliberal}

El Título Sexto sobre Combate a la Corrupción incluye el concepto de "austeridad" y lo relaciona directamente con las ideas de moderación, eficiencia, eficacia, economía, racionalidad, etcétera, que son concepciones tradicionalmente utilizadas para reforzar la retórica neoliberal que aboga por "reducir los gastos del gobierno" con objeto de disminuir recursos de los programas sociales y priorizar los grandes intereses empresariales y financieros. Por ejemplo, la Secretaría de Desarrollo Social (Sedesol) en la víspera a la aprobación de esta Constitución anunciaba ya con bombo y platillo que para 2017 se aplicarían importantes recortes a programas sociales prioritarios como el programa de Abasto Social de Leche Liconsa; el de Abasto Rural de Diconsa; el Programa de Atención a Jornaleros Agrícolas, el programa de Seguro de Vida para Jefas de Familia, la Pensión para Adultos Mayores e incluso los programas de los Comedores Comunitarios, entre otros. ${ }^{13}$

De manera lamentable el artículo con el que abre el título sexto del supuesto "Buen Gobierno y Buena Administración” en el párrafo 4 del nume-

12 Tesis la. LXXVIII/2016, Gaceta del Semanario fudicial de la Federación, Décima Época, t. I, marzo de 2016, p. 994.

13 Baptista, Diana, "Recortara Sedesol programas de apoyos prioritarios: el más afectado el seguro para jefas de familia", Reforma, 1o. de diciembre de 2016, disponible en: http://wwwereforma.com/libre/acceso/acceso.htm?urlredirect=/aplicaciones/articulo/default. aspx:id=997989. 
ral 1 señala: "Los principios de austeridad, moderación, honradez, eficiencia, eficacia, economía, transparencia, racionalidad y rendición de cuentas, son de observancia obligatoria en el ejercicio y asignación de los recursos de la Ciudad que realicen las personas servidoras públicas". ${ }^{14}$

Ello podría significar que si ciertos servidores públicos de filiación conservadora o neoliberal consideran que un programa de comedores comunitarios, de apoyo a madres solteras o a niños discapacitados, por citar sólo 3 ejemplos, no cumplen con el principio de "eficiencia", de "economía" o el de "racionalidad" en la "asignación de los recursos públicos" los administradores simplemente podrán optar, bajo el amparo de esta Constitución, por cancelarlos, dado que de acuerdo a un análisis textual estos principios son "de observancia obligatoria".

Como propuesta alternativa, siempre existió la propuesta de una "Austeridad Republicana" que si bien adelgazaría el gasto burocrático del gobierno y los gastos innecesarios y onerosos, siempre y en todo lugar respetaría e incluso aumentaría de forma decidida los derechos sociales de la población en el marco del principio de progresividad de los derechos humanos. La fundamentación jurídica utilizada al respecto abunda tanto en tratados internacionales como en legislaciones de otros estados. Por ejemplo, podemos citar los siguientes elementos:

Artículo 2o. del Pacto Internacional de Derechos Económicos, Sociales y Culturales. Cada uno de los Estados Partes en el presente Pacto se compromete a adoptar medidas, tanto por separado como mediante la asistencia y la cooperación internacionales, especialmente económicas y técnicas, hasta el máximo de los recursos de que disponga, para lograr progresivamente, por todos los medios apropiados, inclusive en particular la adopción de medidas legislativas, la plena efectividad de los derechos aquí reconocidos. ${ }^{15}$

Artículo 37 de la Constitución Boliviana. El Estado tiene la obligación indeclinable de garantizar y sostener el derecho a la salud, que se constituye en una función suprema y primera responsabilidad financiera. Se priorizará la promoción de la salud y la prevención de las enfermedades. ${ }^{16}$

14 Asamblea Constituyente, Constitución Política de la Ciudad de México, 2017, artículo 60, numeral 1, párr. 4.

15 Pacto Internacional de Derechos Económicos, Sociales y Culturales, 1976, artículo 2o., numeral 1.

16 Constitución Política del Estado Plurinacional de Bolivia, 2009, artículo 37.

Esta obra está bajo una Licencia Creative Commons

Atribución-NoComercial-SinDerivar 4.0 Internacional, IIJ-UNAM.

Boletín Mexicano de Derecho Comparado, núm. 152, pp. 869-912. 
Artículo 85 de la Constitución Ecuatoriana. La formulación, ejecución, evaluación y control de las políticas públicas y servicios públicos que garanticen los derechos reconocidos por la Constitución, se regularán de acuerdo con las siguientes disposiciones:

1. Las políticas públicas y la prestación de bienes y servicios públicos se orientarán a hacer efectivos el buen vivir y todos los derechos, y se formularán a partir del principio de solidaridad.

3. El Estado garantizará la distribución equitativa y solidaria del presupuesto para la ejecución de las políticas públicas y la prestación de bienes y servicios públicos. ${ }^{17}$

\section{Prescripción de los delitos de corrupción}

El presidente de la Comisión se negó a incorporar también otra propuesta de gran valía en el sentido de que los delitos y las faltas de corrupción no debían prescribir. El argumento de la Comisión aseguraba que forzosamente se tenía que otorgar un plazo para la prescripción de los delitos por el principio de "racionalidad". ${ }^{18}$ Pero paradójicamente también reconocía que la Constitución no establece un límite máximo. Una y otra vez se argumentó en el seno de esta comisión y en el pleno de la Asamblea Constituyente que los tratados internacionales y legislación comparada efectivamente permiten detener indefinidamente la prescripción de los delitos por corrupción.

$\mathrm{Al}$ respecto se ofrecieron los argumentos contenidos en la Convención de las Naciones Unidas contra la Corrupción (ONU), que señala:

Artículo 29. Prescripción. Cada Estado Parte establecerá, cuando proceda, con arreglo a su derecho interno, un plazo de prescripción amplio para iniciar procesos por cualesquiera de los delitos tipificados con arreglo a la presente Convención y establecerá un plazo mayor o interrumpirá la prescripción cuando el presunto delincuente haya eludido la administración de justicia. ${ }^{19}$

17 Constitución de la República del Ecuador, 2008, artículo 85.

18 Véase Proyecto de Dictamen de la Comisión de Buen Gobierno, Combate a la Corrupción y Régimen de Responsabilidades de los Servidores Públicos, con Proyecto de Título Quinto de la Constitución Política de la Ciudad de México, disponible en: http:// gaceta.diputados.gob.mx/ACCM/GP/20161129-I.pdf.

19 Asamblea General de la Organización de las Naciones Unidas, Convención de las Naciones Unidas contra la Corrupción, 2003, artículo 29.

Esta obra está bajo una Licencia Creative Commons Atribución-NoComercial-SinDerivar 4.0 Internacional, IIJ-UNAM. Boletín Mexicano de Derecho Comparado, núm. 152, pp. 869-912. 
En relación a la legislación comparada, ofrecimos siempre los siguientes artículos

Artículo 233 de la Constitución Ecuatoriana - Ninguna servidora ni servidor público estará exento de responsabilidades por los actos realizados en el ejercicio de sus funciones, o por sus omisiones, y serán responsables administrativa, civil y penalmente por el manejo y administración de fondos, bienes o recursos públicos. Las servidoras o servidores públicos y los delegados o representantes a los cuerpos colegiados de las instituciones del Estado, estarán sujetos a las sanciones establecidas por delitos de peculado, cohecho, concusión y enriquecimiento ilícito. La acción para perseguirlos y las penas correspondientes serán imprescriptibles y, en estos casos, los juicios se iniciarán y continuarán incluso en ausencia de las personas acusadas. Estas normas también se aplicarán a quienes participen en estos delitos, aun cuando no tengan las calidades antes señaladas. ${ }^{20}$

Artículo 112 de la Constitución de Bolivia. Los delitos cometidos por servidores públicos que atenten contra el patrimonio del Estado y causen grave daño económico, son imprescriptibles y no admiten régimen de inmunidad. ${ }^{21}$

Artículo 29 de la Convención de la Naciones Unidas Contra la Corrupción. Cada Estado Parte establecerá, cuando proceda, con arreglo a su derecho interno, un plazo de prescripción amplio para iniciar procesos por cualesquiera de los delitos tipificados con arreglo a la presente Convención y establecerá un plazo mayor o interrumpirá la prescripción cuando el presunto delincuente haya eludido la administración de justicia. ${ }^{22}$

Por otro lado, siempre sostuvimos que la propia Suprema Corte de Justicia de la Nación ha establecido que los tratados internacionales tienen incluso rango constitucional y que están por arriba de las leyes generales.

\section{Legalización de las asociaciones público-privadas}

Una de las vías más sencillas para canalizar recursos públicos hacia empresas vinculadas a los mismos funcionarios públicos es por medio de la figura de las asociaciones público-privadas. Por ejemplo, recientemente

20 Constitución de la República del Ecuador, 2008, artículo 204.

21 Constitución Política del Estado Plurinacional de Bolivia, 2009, artículo 112.

22 Asamblea General de la Organización de las Naciones Unidas, Convención de las Naciones Unidas contra la Corrupción, 2003, artículo 29).

Esta obra está bajo una Licencia Creative Commons

Atribución-NoComercial-SinDerivar 4.0 Internacional, IIJ-UNAM.

Boletín Mexicano de Derecho Comparado, núm. 152, pp. 869-912. 
se ha documentado que el exsecretario de Salud de Sinaloa otorgó contratos de gobierno por 87 millones de pesos a sus propias empresas y que esto ocurrió a través de figuras como las asociaciones público-privadas. ${ }^{23}$

Además, de que esta corrupción se acompaña de innumerables conflictos de interés, cuando se trata del patrimonio público (vender o ceder un bien que está bajo el dominio de la nación y al cuidado de su Estado), permitir que el Estado se vuelva un actor privado como todos y pueda hacer transacciones de carácter privado no sólo choca con la letra de nuestra carta magna, sino también contra toda lógica jurídica.

Un bien público es, por definición, un bien que está fuera de la esfera de los privados. Citemos de manera breve el artículo 27 constitucional: "La nación tendrá en todo tiempo el derecho de imponer a la propiedad privada las modalidades que dicte el interés público". ${ }^{24}$

El razonamiento anterior también tiene sustento en el artículo 749 del Código Civil para el Distrito Federal que a la letra reza: "Están fuera del comercio por su naturaleza las que no pueden ser poseídas por algún individuo exclusivamente, y por disposición de la ley, las que ella declara irreductibles a propiedad particular". ${ }^{25}$

Es verdad que se puede argumentar que el concepto "privatización" desde la ciencia política, la administración o incluso la economía, puede ser ambiguo y debatible. Sin embargo, si analizamos el objeto jurídico de la cosa o el servicio a privatizar y desde la perspectiva jurídica, el resultado es mucho más preciso y el concepto "privatizar" resulta sencillo de entender. Así tenemos que cuando un bien público tiene como objeto pasar a manos de un privado, estamos frente a un acto jurídico privatizador, cualquiera que haya sido el modo o manera en que se realice el acto.

Permitir y, peor aún, constitucionalizar las asociaciones público-privadas, es negar y desentender las principales funciones que tiene el Estado. Como lo son los servicios públicos, el mantenimiento de infraestructura, tareas de índole administrativo (como las infracciones de tránsito), un medio ambiente sano, entre muchas otras responsabilidades públicas y estatales.

23 Soto, Gabriela y Giusti, Heriberto, "Exsecretario de Salud de Sinaloa dio contratos por 87.2 mdp a su propia red empresarial", Animal Politico, 3 de julio de 2017, disponible en: $g 00 . g l / q V j k 9 E$.

24 Constitución Política de los Estados Unidos Mexicanos, 1917, artículo 27, párr. 3.

25 Código civil para el Distrito Federal, 1928, artículo 749.

Esta obra está bajo una Licencia Creative Commons Atribución-NoComercial-SinDerivar 4.0 Internacional, IIJ-UNAM. Boletín Mexicano de Derecho Comparado, núm. 152, pp. 869-912. 
De forma lamentable, esta Constitución ha permitido un retroceso inaceptable al legalizar y, peor aún, constitucionalizar de forma velada las asociaciones público-privadas, dado que en el artículo 64, numeral 8, se señala lo siguiente: "La ley regulará las responsabilidades correspondientes a las relaciones contractuales multianuales entre los sectores público, social, privado y organizaciones ciudadanas para mejorar el bienestar social y la gestión urbana, asegurando audiencias y máxima publicidad". ${ }^{26}$

Esto es a todas luces inaceptable y anticonstitucional. Los contratos de asociación público-privada que se establecen entre un gobierno (federal, estatal o municipal) y una empresa o persona moral son anticonstitucionales. En estos contratos la empresa contratista financia, construye y administra una obra y/o un servicio público durante el período especificado en el contrato, generalmente de 25 a 40 años. En otras palabras, se trata precisamente de "relaciones contractuales multianuales" y estas obras o activos son propiedad de la empresa contratista durante el tiempo de duración del contrato cuando eventualmente pueden ser trasferidas al gobierno. Es de señalar que el tiempo de duración del contrato suele corresponder al tiempo de vida útil de la obra, o sea cuando se transfiere no tiene uso.

Como contraprestación el gobierno efectúa un pago mensual al contratista durante el tiempo del contrato o, alternativamente, le cede al contratista los ingresos por el servicio prestado. Este tipo de contratos anticonstitucionales se han venido aplicando en cualquier obra o servicio públicos; por ejemplo, carreteras, medios de transporte, hospitales, escuelas, universidades, procesamiento de basura, tratamiento y distribución de agua, cárceles, proyectos de investigación científica, etcétera.

La esencia de estos contratos es que el gobierno trasfiere una responsabilidad pública a la empresa privada. Es una forma novedosa y velada de privatización al involucrar empresas y financiadores privados que evidentemente apuestan por importantes ganancias para ellos. Los contratos de asociación público-privada se inventaron para darle la vuelta a las reglas sobre el techo máximo de endeudamiento público o gubernamental que el Tratado de Maastricht de la Unión Europea fijó en $60 \%$ del PIB. La maniobra consiste en que el endeudamiento a través de los contratos APP no se registra como deuda pública ya que formalmente

26 Asamblea Constituyente, Constitución Política de la Ciudad de México, 2017, artículo 64, numeral 8.

Esta obra está bajo una Licencia Creative Commons

Atribución-NoComercial-SinDerivar 4.0 Internacional, IIJ-UNAM.

Boletín Mexicano de Derecho Comparado, núm. 152, pp. 869-912. 
es una deuda del contratista APP que se paga y registra por el gobierno como gasto corriente. $\mathrm{O}$ sea, se trata de un mero arreglo contable ya que el gobierno está obligado a pagarlo a plazos pero a un costo mucho más alto; en otras palabras, se trata de legalizar la corrupción estructural a través de nuevas formas de privatización. ${ }^{27}$

La historia reciente de México nos ha demostrado que dejar en manos de empresas privadas funciones propias del Estado trae consecuencias negativas, que van desde el encarecimiento de los servicios, la mala calidad, la entrega de bienes públicos a precios de remate, etcétera. Como muestra un botón: los ferrocarriles fueron privatizados y desaparecieron como medio de transporte de pasajeros, los bancos pasaron a manos privadas lo que trajo como consecuencia, entre muchos otros problemas, el poco acceso al crédito barato, la entrega de Pemex y los recursos naturales a transnacionales; podríamos seguir enumerando los miles de casos, pero con estos ejemplos es suficiente la necesidad de prohibirlos.

Atendiendo la Carta de derechos y deberes económicos de los Estados que en su capítulo dos, artículo lo., establece que: "Los Estados tienen el derecho soberano e inalienable de elegir su sistema económico, así como político, social y cultural, de acuerdo con la voluntad de su pueblo". ${ }^{28}$

El objetivo primordial de todos los Estados democráticos es la búsqueda del bienestar de su pueblo. Aquel Estado que no cumpla con este mandato, está incurriendo en faltas graves no sólo de índole nacional sino también internacional. La privatización disfrazada de asociación públicaprivada no persigue el bien común sino el particular, el de unos cuantos. Por todas estas razones se convierte en una obligación además de la necesidad de abolirlas de la Ciudad de México, para garantizar el bienestar de todos sus residentes.

\section{Nula transparencia del sector privado}

Señalar a los actores privados como sujetos centrales en los actos de corrupción es fundamental, ya que normalmente se afirma que son los

27 Véase Sandoval Ballesteros, Irma Eréndira, Interés público, asociaciones público privadas y poderes fácticos, UNAM, Instituto de Investigaciones Sociales, Laboratorio de Documentación y Análisis de la Corrupción y la Transparencia, 2015.

28 Asamblea General de la Organización de las Naciones Unidas, Carta de derechos y deberes económicos de los Estados, 1974, capítulo 2, artículo 1 o.

Esta obra está bajo una Licencia Creative Commons Atribución-NoComercial-SinDerivar 4.0 Internacional, IIJ-UNAM. Boletín Mexicano de Derecho Comparado, núm. 152, pp. 869-912. 
servidores públicos los principales responsables, lo cual elimina la responsabilidad de los particulares en dichas acciones. Asimismo, es fundamental recordar que los individuos no actúan solos, por lo general tienen el respaldo de sus empresas para llevar acabo dichos ilícitos, ya que con ellos garantizan una ganancia tanto para el individuo como para la corporación.

Luego de la gran crisis de 1930, el sociólogo estadounidense Edwin Sutherland revolucionó el mundo intelectual con su tesis de los "delitos de cuello banco". En una conferencia argumentó que según sus investigaciones las grandes corporaciones económicas violaban permanentemente las leyes vigentes y en particular en materia tributaria, de monopolio, aduanera, de defensa del consumidor, de relaciones laborales y manipulación financiera. Y que esos delitos no eran investigados, y muchas veces ni siquiera denunciados. Con base en esta tesis, cuestionó la validez de las estadísticas oficiales sobre el delito, ya que se construían sobre las denuncias, y también las posibles causas de la delincuencia que estaban enfocadas hacia la pobreza, la falta de instrucción o el hacinamiento.

El caso Duarte es sólo la joya de la corona de una larga y triste lista de casos de corrupción que se han dado en México desde hace décadas. El caso de su esposa, Karime Macías Tubilla, quien ordenó al abogado fiscalista, Alfonso Ortega, constituir empresas en México y en el extranjero, con las cuales Javier Duarte adquirió decenas de inmuebles, demuestra el modus operandi de la red de corrupción manejado por el exgobernador.

En la gestión de Duarte, su esposa Karime Macías Tubilla era la fuerza política del gobernador, pero Moisés Mansur, el operador financiero. No tenía cargo público, pero, según empresarios veracruzanos, si alguien quería hacer obra en el estado, tenía que pasar por él. "Designaba a quién se le daba la obra y decidía en qué términos", dijo una persona que conocía el mecanismo de operación.

Recientemente, se dio a conocer que en el estado de Puebla el gobierno de Rafael Moreno Valle ha comprometido la totalidad de los recursos recaudados por concepto de Impuesto sobre Erogaciones por Remuneración al Trabajo Personal durante los próximos 50 años a un fideicomiso administrado por la empresa Evercore, propiedad de Pedro Aspe, exsecretario de Hacienda durante el sexenio de Carlos Salinas de Gortari.

En la capital del país hay constantes rumores con respecto a quiénes serían los verdaderos dueños de las diferentes empresas que entran en rela- 
ciones contractuales con el gobierno de la Ciudad de México; por ejemplo, las empresas que manejan los parquímetros, las grúas o las foto-multas, así como las empresas responsables por administrar los espacios de los "bajo puentes", manejar los centros verificadores de los niveles de contaminación de los automóviles y dar mantenimiento a las patrullas de la policía capitalina, entre muchos otros contratos y servicios privados.

La sospecha fundada es que estos negocios realizados al amparo del poder público pertenecerían a los familiares y los amigos de los funcionarios públicos, quienes posteriormente, sobre todo durante épocas electorales, piden que se devuelva el favor de haber otorgado los permisos y contratos correspondientes con el otorgamiento de "moches" u otro tipo de favores políticos, personales o empresariales.

En general, los secretos bancarios, comerciales o de cualquier otra índole han sido tremendamente perjudiciales para la sociedad mexicana debido a que detrás de ellos se ha hecho mal uso del dinero público manejado por particulares y se han encubierto ilícitos. No obstante, no se está proponiendo develar los datos personales de las personas físicas, sino lo que se busca es transparentar el uso de recursos cuando son recaudados al amparo del poder público. ${ }^{29}$

Desafortunadamente, los secretos bancarios y similares han servido por lo general para proteger intereses deshonestos y poco claros. Por lo anterior se propone prohibirlos y con ello hacer realmente efectiva la fiscalización ciudadana. Como referencia jurídica tenemos la Convención de las Naciones Unidas Contra la Delincuencia Organizada que en su artículo 12, párrafo seis dice: “...cada Estado Parte facultará a sus tribunales u otras autoridades competentes para ordenar la presentación o la incautación de documentos bancarios, financieros o comerciales. Los Estados Parte no podrán negarse a aplicar las disposiciones del presente párrafo amparándose en el secreto bancario".

Es entonces de suma importancia transparentar y hacer pública la estructura de propiedad así como el manejo financiero de todas y cada una de las empresas que entran en relaciones contractuales con el gobierno de

29 Véanse Sandoval Ballesteros, Irma Eréndira, "From Institutional to Structural Corruption: Rethinking Accountability in a World of Public-Private Partnerships", Institutional Corruption Series, Harvard University, 2013; Sandoval Ballesteros, Irma Eréndira, "Enfoque de la Corrupción 'Estructural': Poder, impunidad y voz ciudadana", Revista Mexicana de Sociología, UNAM, Instituto de Investigaciones Sociales, 2016, pp. 119-152. 
la Ciudad de México. No es suficiente solamente transparentar los recursos públicos que se entreguen a los fideicomisos y las entidades de derecho privado, sino que habría que transparentar todas las operaciones financieras de estas empresas. Ello porque una gran parte de los recursos recaudados por estas empresas es, estrictamente hablando, recurso privado, pero lo que permite la existencia de estas ganancias privadas es su relación con y protección del gobierno. ${ }^{30}$

\section{Conflictos de intereses}

Echando completamente por la borda una propuesta de redacción sobre responsabilidades penales y administrativas y conflictos de interés que ya se encontraba consensada por la Mesa Directiva de la Comisión, que por cierto de forma autoritaria quedó fuera de la primera publicación del proyecto de dictamen y que por lo tanto debió de refrendarse inclusive a través de la única "fe de erratas" del proyecto de dictamen, en la sesión del 2 de diciembre se dio un claro albazo al espíritu de esa redacción y de forma autoritaria el senador Ríos la sustituyó por otra que dejó demasiado laxo y abierto el abordaje de los conflictos de intereses.

El tema es sumamente relevante para el combate de la corrupción en nuestro país. Los conflictos de interés emergen cuando los gobernantes, representantes y servidores públicos de alto nivel se encuentran sometidos a pleitesías y compromisos económicos, financieros, familiares o políticos que afectan negativamente el desempeño de sus encargos públicos. ${ }^{31}$

Actualmente en México contamos con ciertos artículos incluidos de forma inconexa en las leyes federales y estatales que ciertamente buscan prevenir los conflictos de interés. Algunos ejemplos positivos al respecto son las disposiciones incluidas en el artículo 8o., fracciones XI y XII, de la Ley Federal de Responsabilidades Administrativas de los Servidores Públicos que señala que todo servidor público está obligado a:

30 Sandoval Ballesteros, Irma Eréndira, Rendición de cuentas y fideicomisos: El reto de la opacidad financiera, Auditoria Superior de la Federación, 2007.

31 Véanse Sandoval Ballesteros, Irma Eréndira, "Conflicto de interés", Revista Técnica sobre Rendición de Cuentas y Fiscalización Superior, núm. 1, agosto de 2006, pp. 55-67; Arellano Gault, D. y Zamudio González, L., "Dilemas organizacionales e institucionales de las regulaciones para contener los conflictos de interés en una democracia: una aproximación comparativa entre Canadá, EUA y México”, Convergencia, vol. 16, núm. 49, 2009, pp. 145-173.

Esta obra está bajo una Licencia Creative Commons

Atribución-NoComercial-SinDerivar 4.0 Internacional, IIJ-UNAM.

Boletín Mexicano de Derecho Comparado, núm. 152, pp. 869-912. 
XI. Excusarse de intervenir, por motivo de su encargo, en cualquier forma en la atención, tramitación o resolución de asuntos en los que tenga interés personal, familiar o de negocios, incluyendo aquéllos de los que pueda resultar algún beneficio para él, su cónyuge o parientes consanguíneos o por afinidad hasta el cuarto grado, o parientes civiles, o para terceros con los que tenga relaciones profesionales, laborales o de negocios, o para socios o sociedades de las que el servidor público o las personas antes referidas formen o hayan formado parte.

XII. Abstenerse, durante el ejercicio de sus funciones, de solicitar, aceptar o recibir, por sí o por interpósita persona, dinero, bienes muebles o inmuebles mediante enajenación en precio notoriamente inferior al que tenga en el mercado ordinario, donaciones, servicios, empleos, cargos o comisiones para sí, o para las personas a que se refiere la fracción XI de este artículo, que procedan de cualquier persona física o moral cuyas actividades profesionales, comerciales o industriales se encuentren directamente vinculadas, reguladas o supervisadas por el servidor público de que se trate en el desempeño de su empleo, cargo o comisión y que implique intereses en conflicto. Esta prevención es aplicable hasta un año después de que se haya retirado del empleo, cargo o comisión.

Otras disposiciones similares se encuentran incluidas en el Código Penal, en particular en su artículo 221 (Capítulo IX), que aborda la diferente gama de situaciones en que se presenta el delito de tráfico de influencias cuando, por ejemplo:

I. El servidor público que por sí o por interpósita persona promueva o gestione la tramitación o resolución ilícita de negocios públicos ajenos a las responsabilidades inherentes a su empleo, cargo o comisión, y II. Cualquier persona que promueva la conducta ilícita del servidor público o se preste a la promoción o gestión a que hace referencia la fracción anterior. III. El servidor público que por sí, o por interpósita persona indebidamente, solicite o promueva cualquier resolución o la realización de cualquier acto materia del empleo, cargo o comisión de otro servidor público, que produzca beneficios económicos para sí o para su cónyuge, descendientes o ascendientes, parientes por consanguinidad o afinidad hasta el cuarto grado, a cualquier tercero con el que tenga vínculos afectivos, económicos o de dependencia administrativa directa, socios o sociedades de las que el servidor público o las personas antes referidas formen parte. 
También tenemos referencias explícitas en la Ley de Adquisiciones, Arrendamientos y Servicios del Sector Público, la Ley Federal de Procedimiento Administrativo, la Ley de Fiscalización y Rendición de Cuentas de la Federación en sus artículos 22 y 101, y las propias directrices con las que cuenta la Auditoría Superior de la Federación para prevenir el Conflicto de Interés. ${ }^{32}$

Sin embargo, hasta el momento desafortunadamente todavía no tenemos un sólo ordenamiento jurídico con jerarquía de ley que de manera coherente y sistemática concentre toda la normatividad relevante atesorada en los códigos de ética, instrumentos legales y referencias constitucionales, relativas a la prohibición y castigo de los conflictos de interés en la gestión de lo público.

La Constitución Política de la Ciudad de México dejo pues escapar una oportunidad estratégica al no avanzar en el fortalecimiento de las disposiciones preventivas y punitivas en materia de conflictos de interés. Nuestra posición siempre fue que la primera Constitución de la Ciudad precisara con mucho mayor detalle qué tipo de conflictos de interés debían prohibirse y hacerse anticonstitucionales, así como las consecuencias jurídicas de violar las prohibiciones existentes.

La redacción que en lo personal propuse y siempre defendí para el artículo de las responsabilidades administrativas y que, como ya hemos referido arriba, fue alevosamente eliminada del dictamen publicado en Gaceta Parlamentaria y posteriormente incluida para su discusión en una fe de $\operatorname{erratas}^{33}$ fue la siguiente:

\section{De las Responsabilidades Administrativas}

7. El Congreso local establecerá una Ley para tipificar y sancionar los casos de conflicto de interés, establecer restricciones a las actividades profesionales de las personas servidoras públicas una vez que se separen de sus cargos, definir los procedimientos para la consulta pública de la identidad de las personas físicas y morales involucradas en el establecimiento y gestión de empresas, así como ordenar la declaración jurada de los servidores públicos sobre sus actividades externas, empleos, inversiones, activos, regalos o bene-

32 Véase Sandoval Ballesteros, Irma Eréndira, "Conflicto de interés", cit., pp. 55-67.

33 Fe de Erratas al Proyecto de Dictamen de La Comisión de Buen Gobierno, Combate a la Corrupción y Régimen de Responsabilidades de los Servidores Públicos, disponible en: http://gaceta.diputados.gob.mx/ACCM/GP/20161129-FE.pdf.

Esta obra está bajo una Licencia Creative Commons

Atribución-NoComercial-SinDerivar 4.0 Internacional, IIJ-UNAM.

Boletín Mexicano de Derecho Comparado, núm. 152, pp. 869-912. 
ficios importantes que puedan dar lugar a un conflicto de intereses respecto de sus atribuciones como funcionarios públicos. También deberá regular las responsabilidades administrativas en que incurran los particulares por el financiamiento ilícito a campañas electorales. La promoción de personas físicas o agrupaciones políticas mediante el uso de recursos públicos tendrá como consecuencia la inhabilitación y las sanciones que determine la legislación penal. Entre las sanciones que se establezcan en la Ley a que se refiere este párrafo, se incluirá la nulidad o revocación de los contratos que se hayan celebrado con entes públicos y las demás que resulten procedentes.

Esta más robusta redacción inspirada en la firme convicción de lo importante que resulta combatir los conflictos de interés fue desechada y sustituida por la laxa e incongruente redacción que hoy presenta el título Sexto de la Constitución de la Ciudad de México y que a la letra reza:

\section{Artículo 64}

6. La Ley determinará los casos en los que se incurra en conflicto de intereses y establecerá las sanciones en la materia que corresponda. Definirá las responsabilidades en que incurran las personas servidoras públicas y en su caso los particulares, personas físicas o morales que no manifiesten la existencia de dichos conflictos y se beneficien económica o políticamente por éstos. ${ }^{34}$

\section{Servicio profesional de carrera}

El artículo 60 de la Constitución señala que el servicio profesional de carrera de los entes públicos "aplicará a partir de los niveles intermedios de la estructura administrativa”. Ello es una aberración ya que deja un margen de acción demasiado amplio al Ejecutivo para restringir el servicio profesional de profesionalización y evaluación únicamente a los niveles con menor responsabilidad en la administración pública de la Ciudad de México. Si bien los más altos mandos (secretario y subsecretario de despacho, por ejemplo) efectivamente podrían estar libres del servicio civil, para garantizar una buena conducción y coordinación de gobierno, todos los otros cargos deberían ser asignados de acuerdo con estrictos principios de mérito y desempeño en el trabajo profesional.

34 Asamblea Constituyente, Constitución Política de la Ciudad de México, 2017, artículo 64, numeral 6. 
Desde hace ya 14 años cuando se aprobó la Ley del Servicio Profesional de Carrera, este importante instrumento se ha prestado a la simulación. Los políticos y gobernantes siguen utilizando el acceso al servicio público más como botín político a repartir con criterios clientelistas que como un verdadero sistema de méritos y habilidades con criterios de ingreso y a través de concursos de oposición abiertos basados en conocimiento y aptitud. ${ }^{35}$

De acuerdo con el Inegi, la administración pública federal está compuesta por 97 instituciones centralizadas, 18 secretarías de Estado y 74 órganos desconcentrados, donde laboraban 1,698,161 servidores públicos. Ya desde 2012, la Auditoria Superior de la Federación realizó una auditoria de desempeño al Servicio Profesional de Carrera del Poder Ejecutivo Federal a través del cual reportó demasiadas incongruencias y deficiencias tanto en relación con los mecanismos de evaluación, ingreso y promoción de los servidores públicos. ${ }^{36}$ La propia Secretaría de la Función Pública (SFP) también ha reconocido el limitado impacto del Servicio Profesional de Carrera, ya que esta institución ha reconocido que, al 31 de diciembre del 2016, únicamente el $2.7 \%$ de la plantilla de la Administración Pública Federal contaba con licenciaturas, posgrados y diplomados en universidades nacionales e internacionales, es decir con méritos y credenciales académicas.

Otro elemento que demuestra el incumplimiento o manipulación del SPC en el ámbito federal con el fin de hacer contrataciones a modo es el hecho de que en noviembre del 2012, el ex presidente Felipe Calderón dio un regalo a su sucesor pues envió al Congreso una serie de reformas y modificaciones al SPG para que el nuevo gobierno de Enrique Peña Nieto pudiera disponer de plazas de alto mando (1,213 plazas de directores generales y 2,409 de directores generales adjuntos), sin que fueran sujeto

35 Véase Zárate Castillo, Arturo, "El servicio profesional de carrera en la administración pública federal", Políticas Públicas, El Colegio de México, 2010, pp. 179-205; Reséndiz, César, "Del compadrazgo a la meritocracia: el servicio profesional de carrera en gobiernos locales", Reelección municipal y rendición de cuentas: ¿cómo lograr el círculo virtuoso?, México, Instituto Mexicano para Competitividad, 2016, pp. 204-218.

36 Auditoria Superior de la Federación, Auditoría de Desempeño: 13-0-40100-07-0137 al Instituto Nacional de Estadística y Geografia Sistema Nacional de Información Estadística y Geográfica GB-124, 2010, disponible en: http://wrww.beta.inegi.org.mx/contenidos/transparencia/contenidos/ doc/ctasf14.pdf.

Esta obra está bajo una Licencia Creative Commons

Atribución-NoComercial-SinDerivar 4.0 Internacional, IIJ-UNAM.

Boletín Mexicano de Derecho Comparado, núm. 152, pp. 869-912. 
de designación por concurso. Con esas reformas, Peña Nieto dispuso de cerca de 6,000 plazas por vía de la designación directa.

Por otro lado, es muy llamativo que la Constitución Política de la Ciudad de México en el establecimiento de este servicio profesional incorpora de forma más bien declarativa el principio de la paridad de género. El problema, sin embargo, es que aquellos concursos de oposición de plazas abiertas indistintamente para hombres y mujeres pueden tender a beneficiar al varón pues no puede dejarse de advertir que las mujeres han sido sometidas a una situación de discriminación que, en general, les niega altos niveles de preparación. Este tipo de problemáticas no están bien abordadas en la Constitución.

Por todo ello resulta paradójico que esta Constitución haya dejado pasar la gran oportunidad de combatir la corrupción por medio del auspicio de una Ley de la Administración Pública que verdaderamente obligase a aplicar el servicio profesional de carrera a todos los cargos y niveles.

\section{Indicadores de desempeño y evaluación}

En tono con la mayor parte del artículo 6o., que centra el "Buen gobierno" y la "buena administración" en declaraciones y repeticiones de viejas normas y buenas intenciones, el capítulo destinado al "Sistema Local Anticorrupción" no incluye ninguna obligatoriedad de aplicar indicadores de desempeño y evaluación.

Los indicadores de desempeño con los que contamos actualmente en todos los niveles del gobierno en México son profundamente deficientes. Ello sumado a la impunidad característica de nuestra cultura administrativa, la opacidad prevaleciente en la administración pública y en especial en la procuración de justicia y la permanente generación de conflictos de interés en todos los niveles de servicio, resulta en la generación del gran círculo vicioso de la corrupción estructural. Precisamente por ello era crucial que la nueva Constitución diera cumplimiento al mandato de la Constitución. Ya han pasado varios años de aquella histórica reforma al artículo 6o. constitucional que por consenso estableció el principio de "máxima publicidad" para la información pública, la obligación de procedimientos expeditos para las solicitudes de acceso a la información, la creación de organismos garantes especializados e independientes y en particular la publicación de indicadores de desempeño en todas las instan-

Esta obra está bajo una Licencia Creative Commons Atribución-NoComercial-SinDerivar 4.0 Internacional, IIJ-UNAM. Boletín Mexicano de Derecho Comparado, núm. 152, pp. 869-912. 
cias de gobierno. ${ }^{37}$ Desafortunadamente, a la fecha los poderes federales han hecho caso omiso a estas directrices constitucionales y hoy la recién nacida Constitución de la Ciudad de México no se ha quedado atrás en violentar este importante mandato constitucional.

Los servidores públicos están acostumbrados a rendir informes de sus actividades en lugar de ofrecer algunos mínimos indicadores de su desempeño de forma cotidiana. ${ }^{38} \mathrm{~A}$ veces parece que lo importante es la cantidad de acciones realizadas y no la calidad o el impacto real que éstas logran en la sociedad. Necesitamos emprender una verdadera revolución en la materia en el país. La Constitución de la Ciudad abdicó está importante responsabilidad. Además, muchas de las actas, acuerdos y convenciones internacionales de las cuales nuestro país es ya signatario nos obligan a incluir indicadores de desempeño en nuestra normatividad. Así que en esta materia la Constitución Política de la Ciudad de México no solamente está incumpliendo con la Constitución federal mexicana sino también con los compromisos internacionales ${ }^{39}$ asumidos por el Estado mexicano en su conjunto que desde luego comprometen a las autoridades de la Ciudad de México frente a la comunidad internacional. El problema, como siempre, fue que no existió en la Asamblea Constituyente la voluntad política para romper de tajo con la corrupción estructural.

\section{SIMULACIÓN GONSTITUGIONAL Y LEYES SECUNDARIAS}

Ya hemos señalado que el diseño constitucional que ofrece la Constitución en materia de combate a la corrupción es incompleto y deficiente, pero

37 Véase Sandoval Ballesteros, Irma Eréndira, "Hacia un proyecto democrático-expansivo de transparencia", Revista Mexicana de Ciencias Políticas y Sociales, septiembre-diciembre de 2013, pp. 103-134.

38 Véase Sandoval Ballesteros, Irma Eréndira, "Las máscaras de la transparencia en el marco de la transición democrática mexicana", en Uvalle, Ricardo, Rumbos de la transparencia en México, UNAM, 2011, pp. 229-255.

39 Entre otros somos signatarios de la Convención de las Naciones Unidas contra la Corrupción, la Convención Interamericana contra la Corrupción, y la Convención de la OCDE contra el Soborno de Los Funcionarios Públicos Extranjeros en las Transacciones Comerciales Internacionales entre otros, estos tres instrumentos establecen la obligatoriedad de indicadores de desempeño y evaluación. Cfr. Rojas Amandi, Víctor Manuel, "Las obligaciones internacionales de México y el nuevo Sistema Nacional Anticorrupción”, Revista Mexicana de Política Exterior, núm. 109, enero-abril de 2017, pp. 181-223.

Esta obra está bajo una Licencia Creative Commons

Atribución-NoComercial-SinDerivar 4.0 Internacional, IIJ-UNAM.

Boletín Mexicano de Derecho Comparado, núm. 152, pp. 869-912. 
aún más preocupante es que ese mermado alcance quedó reducido a su mínima expresión con la aprobación el 17 de julio de 2017 en la Asamblea Legislativa de la Ciudad de México de 11 leyes secundarías destinadas a integrar el Sistema Local Anticorrupción. Sostenemos que todo ello era más que predecible desde la redacción de la Constitución y que estos yerros se pudieron haber evitado de haberse aprobado el Cuarto Poder Ciudadano. Por ello, en lo que sigue revisaremos primero el deficiente y poco arrojado texto de la Constitución, después revisaremos la incoherente y politizada normatividad secundaria que se generó y que ha dado origen al sistema anticorrupción de la CDMX, para dar paso, finalmente al análisis contrafactual del Cuarto Poder Ciudadano.

En la Constitución se señala que el Control Interno tendrá un titular designado por la mayoría calificada del Congreso de entre una terna enviada por el Jefe de Gobierno, removible por este mismo aunque el Congreso podría objetar la remoción mediante el voto una vez más de las dos terceras partes de los diputados presentes. El control interno permite contar con "contralores ciudadanos" con facultad de impugnar las resoluciones de los contralores internos. Sin embargo, no hay obligatoriedad de incluir la figura de los contralores ciudadanos ya que su carácter será meramente "honorífico":

Artículo 61

$3 \ldots$

Esta secretaría contará con un área de contralores ciudadanos que realizarán sus funciones de manera honorífica, por lo que no percibirán remuneración alguna; serán nombrados junto con el órgano interno de control y coadyuvarán en los procesos de fiscalización...

De acuerdo a esta Constitución, el Sistema Anticorrupción debe contar con un Comité Coordinador compuesto por los titulares de la Fiscalización Superior, el Fiscal Anticorrupción, el Tribunal de Justicia Administrativa, el Instituto de Transparencia, el Consejo de Evaluación y el órgano de control del Congreso, así como el Secretario de Control Interno, un consejero de la Judicatura y uno del Comité de Participación Ciudadana del Sistema, quien en teoría lo debería presidir. El Sistema tiene un Secretariado Ejecutivo que funciona como órgano descentrali- 
zado del gobierno designado por el Comité Coordinador a propuesta de su presidente. ${ }^{40}$

A su vez, el Comité de Participación Ciudadana se integra con cinco personas, para cinco años de función, sin reelección, con capacidad para recibir denuncias del público y para presentar denuncias. ${ }^{41}$ La Fiscalización Superior ${ }^{42}$ podrá llevar a cabo fiscalizaciones en todo momento y "podrá solicitar información del ejercicio en curso respecto de procesos concluidos". La Constitución señala que el fiscalizador superior será designado por las dos terceras partes de los miembros del presentes, mediante convocatoria abierta. La Fiscalización Superior podrá revisar ejercicios anteriores sin que se vuelva a abrir a revisión toda la cuenta correspondiente.

Hasta aquí con la Constitución todo va medianamente bien en teoría. El problema es que muchas de las normas secundarías que constituirán el andamiaje normativo del Sistema Local Anticorrupción fueron aprobadas al vapor el 17 de julio pasado únicamente con el apoyo de las bancadas del PRI, PAN y PRD. Estos partidos minoritarios no consiguieron el respaldo de la fuerza política más numerosa tanto en la originaria Asamblea Constituyente como en la Asamblea Legislativa del Distrito Federal (ALDF) y estos partidos no representativos de la mayor parte de la ciudadanía vulneraron la Constitución recientemente aprobada. Por ejemplo, la figura del secretario técnico del Sistema Anticorrupción ya no será nombrada por el Comité Coordinador del Sistema Local Anticorrupción de entre una terna propuesta por el flamante y estéril Comité de Participación Ciudadana (CPG), como a nivel federal lo establece la Ley General del Sistema Nacional Anticorrupción (SNA), sino por la Asamblea Legislativa a partir de una terna propuesta ni más ni menos que por el propio Jefe de Gobierno, lo cual reduce esta importante designación al nivel de una mera simulación.

Las leyes secundarias establecen también que el Fiscal Anticorrupción sea ratificado por mayoría simple de la ALDF a pesar de que la propia Constitución mandata que ello debe hacerse por mayoría calificada; por lo tanto, podría señalarse que son instrumentos normativos anticonstitu-

40 Asamblea Constituyente, Constitución Política de la Ciudad de México, 2017, artículo 63, numeral 4.

41 Ibidem, artículo 63, numeral 3.

42 Ibidem, artículo 62.

Esta obra está bajo una Licencia Creative Commons

Atribución-NoComercial-SinDerivar 4.0 Internacional, IIJ-UNAM.

Boletín Mexicano de Derecho Comparado, núm. 152, pp. 869-912. 
cionales. Esta normatividad también permite ejercicios de simulación en el nombramiento y designación del fiscal especializado en materia de corrupción, el secretario de la Contraloría General, el secretario técnico del Sistema, así como en la designación de los magistrados de la Sala Superior y de la Sala Ordinaria del Tribunal de Justicia Administrativa. En otras palabras, los cargos más importantes del sistema local anticorrupción se entregarán en charola de plata a los partidos políticos y funcionarios de gobierno lo cual anula por completo la necesaria independencia que debe tener un sistema de esta naturaleza.

Aun después de esta controvertida aprobación legislativa que aquí reseñamos hubo más irregularidades en el proceso de dictaminación ya que el 1o. de septiembre el Jefe de Gobierno, Miguel Ángel Mancera, para promulgar el decreto, publicó en la Gaceta Oficial del Distrito Federal una versión totalmente transformada de los dictámenes de ley aprobados por la ALDF. En la publicación oficial se incluye un procedimiento no aprobado por el pleno de la ALDF que permite que el Jefe de Gobierno sea quien decida quién conformará la terna de los candidatos a fiscal anticorrupción y secretario técnico del Sistema, y no como había sido votado por la ALDF que la terna oficial provenga de las comisiones de Transparencia y Combate a la Corrupción y de Rendición de Cuentas, y Vigilancia de la Auditoria Superior local. Ello deja, una vez más, en manos del actual Jefe de Gobierno prácticamente la mayoría de las decisiones importantes y nombramientos.

Asimismo, el marco jurídico publicado abre la posibilidad de que el actual contralor, Eduardo Rovelo, persona de toda la confianza del Jefe de Gobierno, sea secretario de la Contraloría General por siete años más, prorrogables por un periodo igual, y le deja al órgano legislativo la facultad para ratificar ese y otros nombramientos, como el de fiscal anticorrupción, una vez más a propuesta del Jefe de Gobierno. La normativa aprobada el 17 de julio por la ALDF no contemplaba la participación de los actuales funcionarios para lograr la independencia y autonomía necesarias. Sin embargo el artículo 3o. de la Ley Orgánica de la Administración Pública de la Ciudad que se publicó en la Gaceta establece que en el nombramiento y ratificación del secretario de la contraloría, el Jefe de Gobierno y la Asamblea Legislativa podrán considerar al titular de la Contraloría General en funciones a la entrada en vigor de ese decreto. 
Otra adecuación a modo realizada a la normatividad es que se permite la reelección hasta por siete años para el para el fiscal anticorrupción lo que arrojaría un promedio de duración de este encargo de 14 años, y para el secretario técnico de cinco años, con posibilidad de quedarse en total una década. No contento con controlar estos dos importantes nombramientos, el Jefe de Gobierno también busca influir en la definición de quienés conformarían el Comité de Participación Ciudadana, ya que en la publicación oficial se eliminó por completo un párrafo del artículo 40 de la Ley del Sistema Anticorrupción en el que se faculta a las comisiones parlamentarias de Transparencia y Combate a la Corrupción y de Rendición de Cuentas y Vigilancia de la Auditoría Superior de la Ciudad de México para proponer a los integrantes de dicho comité. Así la "imparcialidad" de este mínimo ingrediente de ciudadanía queda completamente anulada.

Como colofón y en el colmo de la incongruencia con el tema del combate a la corrupción, en la fracción IV del artículo noveno de la Ley del Sistema Anticorrupción, se omitió el principio de publicidad de las recomendaciones del Comité Coordinador para las medidas de prevención de faltas administrativas y hechos de corrupción de los entes públicos, por lo que no habrá garantía de que estos documentos serán públicos.

Finalmente, otra evidencia de la violación a la Constitución por parte de esta legislación secundaría es que el supuesto "principio de austeridad" incluido en la Constitución no fue respetado en lo más mínimo. Por ejemplo, en la Ley Orgánica del Tribunal de Justicia Administrativa de la Ciudad destaca la conformación de cinco salas jurisdiccionales. Cada una de las cinco salas que estarán encargadas de resolver sobre juicios derivados de actos de autoridad emitidos por la administración pública capitalina, contará a su vez con tres magistrados y una gran cantidad de recursos humanos, lo que desde ya supera con creces la burocracia establecida en la legislación federal donde sólo se contemplan tres salas. Además del pésimo diseño institucional, el resultado previsible será una burocracia crecida y onerosa que poco ayudará a la generación de una cultura administrativa proba y libre de corrupción.

La fortaleza de un sistema anticorrupción no puede provenir de mayor burocracia, de mayor clientelismo político, ni de mayor captura en los procesos de designación de los servidores públicos a cargo de ese sistema, sino de una plena y genuina democratización y ciudadanización de los ór-

Esta obra está bajo una Licencia Creative Commons

Atribución-NoComercial-SinDerivar 4.0 Internacional, IIJ-UNAM.

Boletín Mexicano de Derecho Comparado, núm. 152, pp. 869-912. 
ganos de control, de impartición de justicia y de rendición de cuentas. La propuesta del Cuarto Poder Ciudadano era lo único que desde la Asamblea Constituyente hubiera garantizado la independencia, la democracia y habría evitado la simulación.

\section{Conclusión: Guarto Poder Giudadano}

Todas las evaluaciones nacionales e internacionales demuestran que la alternancia en el poder, o lo que algunos equívocamente han llamado "transición a la democracia", no ha tenido gran impacto en el combate a la corrupción. Más allá de avances simbólicos y normativos en materia de transparencia, la rendición de cuentas constituye una deuda histórica de la democracia hacia el pueblo de México. La corrupción florece gracias al ejercicio, sin límites democráticos ni jurídicos, de los poderes formales y fácticos; a la debilidad de las instituciones que tendrían que controlar a esos poderes, y a la insuficiencia o, en nuestro caso, inexistencia de mecanismos de participación ciudadana que le permitan a la sociedad vigilar y frenar el abuso de tales poderes.

Frente a este preocupante escenario de corrupción e impunidad, la seriedad del fenómeno de la corrupción estructural no puede continuar siendo minimizada como un asunto de carácter cultural, como el propio titular del Poder Ejecutivo ha insistido de manera irresponsable en los más diversos foros nacionales e internacionales. Hoy más que nunca resulta imprescindible no divorciar el tema de la transparencia de la emergencia nacional que significa atender el combate a la corrupción.

La corrupción, particularmente la de las elites políticas y económicas, no es un accidente que esporádica y súbitamente se presente de forma desafortunada, sino un rasgo inherente y perenne a las estructuras políticas existentes. Para realmente contar con gobiernos, representantes, jueces, empresarios y funcionarios más honestos y transparentes necesitamos construir enfoques heurísticos alternativos que para el análisis de la corrupción vayan más allá del nivel de las "mordidas" y la "burocracia" y no se contenten con la simulación modernizadora de las nuevas tecnologías, las plataformas controladoras e intrusivas y la transparencia de aparador.

Por todo lo anterior en la Ciudad de México se propuso instaurar un Cuarto Poder Ciudadano constitucionalizado. Este tipo de experiencias han sido grandemente exitosas y se han venido implementando ya desde 
hace varios años en los países hermanos del Cono Sur, destacadamente en Bolivia, Uruguay y Ecuador. El cuarto poder ciudadano podría funcionar a partir del establecimiento de consejos cívicos y autónomos que sin interferencia de los otros poderes, y sobre todo de los nuevos poderes fácticos y oligárquicos, tomen en sus manos la verdadera lucha para acabar con la corrupción.

Así encontramos el artículo 204 de la Constitución Ecuatoriana que dice:

El pueblo es el mandante y primer fiscalizador del poder público, en ejercicio de su derecho a la participación.

La Función de Transparencia y Control Social promoverá e impulsará el control de las entidades y organismos del sector público, y de las personas naturales o jurídicas del sector privado que presten servicios o desarrollen actividades de interés público, para que los realicen con responsabilidad, transparencia y equidad; fomentará e incentivará la participación ciudadana; protegerá el ejercicio y cumplimiento de los derechos; y prevendrá y combatirá la corrupción. ${ }^{43}$

En el mismo sentido, el capítulo IV, artículo 273, de la Constitución venezolana que enuncia explícitamente el Poder Ciudadano de la forma siguiente: "El Poder Ciudadano se ejerce por el Consejo Moral Republicano integrado por el Defensor o Defensora del Pueblo, el Fiscal o la Fiscal General y el Contralor o Contralora General de la República". ${ }^{44}$

Para la Ciudad de México, la idea central consistía en instaurar un Sistema Anticorrupción que funcionara como un cuarto poder ciudadano de acción permanente orientado a prevenir, investigar y sancionar actos de corrupción en todos los niveles de gobierno. Para el combate a la corrupción este cuarto poder ciudadano se apegaría en todo momento a los principios establecidos en la Constitución Política de los Estados Unidos Mexicanos, los tratados y convenciones internacionales en la materia, suscritos por el Estado mexicano, y la Constitución Política de la Ciudad de México.

El Sistema Anticorrupción de la Ciudad de México habría sido instituido a través de un Consejo de Honestidad, Participación Ciudadana,

43 Constitución de la República del Ecuador, 2008, artículo 204.

44 Constitución de la República Bolivariana de Venezuela, 1999, artículo 273.

Esta obra está bajo una Licencia Creative Commons

Atribución-NoComercial-SinDerivar 4.0 Internacional, IIJ-UNAM.

Boletín Mexicano de Derecho Comparado, núm. 152, pp. 869-912. 
Austeridad y Control Social completamente ciudadanizado. Se proponía dotarle de personalidad jurídica, y autonomía administrativa, presupuestaria y organizativa.

Los miembros del Consejo de Honestidad, Austeridad y Control Social deberían ser siete ciudadanos imparciales, elegidos por vía del voto universal, directo y secreto, cada siete años sin posibilidad de reelección y ejercerían sus funciones con independencia, de conformidad con la ley que hubiese regido este cuarto poder ciudadano anticorrupción de acción permanente.

Se proponía que las atribuciones constitucionales principales del Consejo de Honestidad, Austeridad, Participación Ciudadana y Control Social fueran entre otras:

a) Implementar mecanismos de participación ciudadana en todas las áreas del gobierno que incluyan entre otros presupuestos participativos, auditorias ciudadanas, plebiscitos, referéndums y todo tipo de instrumentos abiertos de acceso a la justicia.

b) Contar con amplias facultades para investigar y litigar casos de corrupción, pudiendo actuar como parte procesal en las causas que se instauren como consecuencia de sus investigaciones.

c) Proponer leyes y normas orientadas a la protección plena de las garantías laborales, políticas y cívicas de quienes denuncien actos de corrupción en el servicio público, el sector social y las empresas privadas.

d) Seleccionar y designar a los titulares de los organismos especializados de la Ciudad de México, en materias de rendición de cuentas, electoral, judicial y de derechos humanos, incluyendo la Procuraduría General de la Ciudad de México, los ministerios públicos especializados y del fuero común, la Comisión de Derechos Humanos de la Ciudad de México, el Instituto Electoral de la Ciudad de México, el Instituto de Acceso a la Información y Transparencia de la Ciudad de México y la Contraloría Mayor de Hacienda de la Giudad de México

e) Coordinar el Sistema Universal de Declaración Patrimonial y Declaraciones Juradas.

f) Supervisar el cumplimiento de la Ley de Austeridad y Gasto Eficiente para el Gobierno de la Ciudad de México y los Programa de 
Austeridad Republicana y en caso contrario aplicar las sanciones legales que correspondan.

g) Solicitar a cualquier entidad o funcionario público o privado la información que considere pertinente para sus investigaciones. Aquellas personas e instituciones que no colaborasen con el Consejo y se hubieran negado a entregar la información solicitada habrían sido sancionadas de acuerdo con la ley.

h) Establecer indicadores públicos de desempeño, seguimiento y evaluación.

El Consejo de Honestidad, Austeridad, Participación Ciudadana y Control Social estaba destinado a ser el garante del libre acceso al Sistema Universal de Declaración Patrimonial y Declaraciones Juradas. También hubiera estado a cargo de vigilar la observancia de la probidad, rectitud, y la austeridad republicana. Para ello dentro de la propuesta del Cuarto Poder quedaban prohibidos:

a) Los sueldos elevados o excesivos. Ningún funcionario hubiera tenido posibilidad de recibir salarios mayores a los estipulados en la Ley de Austeridad y Gasto Eficiente para el Gobierno de la Ciudad de México y los Programa de Austeridad Republicana.

b) Los bonos y percepciones extraordinarias que siempre representan gastos superfluos para el gobierno.

c) La contratación de servicios médicos privados, seguros de separación individualizado y cajas de ahorro especial para los altos mandos del gobierno, órganos constitucionales autónomos y altas burocracias de partidos políticos y sindicatos.

d) El otorgamiento de pensiones extraordinarias a las establecidas en la Ley de Seguridad Social.

e) Contratación de aeronaves privadas. Todos los servidores públicos sin excepción utilizarán vuelos comerciales.

f) La contratación abusiva de viajes oficiales al extranjero, servicios de asesoría, de telefonía, de viáticos, informáticos, entre otros. 


\section{Anexo. TeXto Alternativo De artículos $60,61,62,63,64$ y 66}

Finalmente ofrecemos al lector la propuesta de mínimos ajustes que con base en lo ya contenido en la Constitución podría mejorar sustancialmente la efectividad del combate a la corrupción. Los cambios se encuentran en cursivas y los subrayados son propuesta de eliminación del texto Constitucional, todos los demás cambios son propuestas de modificación que se sustentan en lo argumentado en el presente artículo.

\section{TíTUlo SEXTO}

\section{DEL BUEN GOBIERNO Y LA BUENA ADMINISTRACIÓN}

\section{Artículo 60}

Garantía del debido ejercicio y la probidad en la Función Pública

1. Se garantiza el derecho a la buena administración a través de un gobierno abierto, integral, transparente, profesional, eficaz, eficiente, austero y resiliente que procure el interés público y combata la corrupción.

El gobierno abierto es un sistema que obliga a los entes públicos a informar a través de una plataforma de accesibilidad universal de datos abiertos apoyada en nuevas tecnologías que garanticen de forma completa y actualizada la transparencia, la rendición de cuentas y el acceso a la información. Asimismo, se deberán generar acciones y políticas públicas orientadas a la apertura gubernamental a fin de contribuir en la solución de los problemas públicos a través de instrumentos ciudadanos participativos, efectivos y transversales. La Ley establecerá los mecanismos para su cumplimiento.

Los principios de austeridad en los gastos burocráticos y de operación, moderación, honradez, eficiencia, eficacia, economía, transparencia, racionalidad y rendición de cuentas son de observancia obligatoria en el ejercicio y asignación de los recursos de la Ciudad que realicen las personas servidoras públicas. En todo caso se observarán los principios de austeridad en los gastos burocráticos y de operación establecidos en el artículo 26 de esta Constitución. Estos principios no se aplicarán si con ellos se suprimen, disminuyen o restringen programas sociales y derechos tutelados en la Constitución y las leyes.

Toda persona Servidora Pública, de conformidad con lo establecido en el artículo 70 del presente título, garantizará en el ejercicio de sus funciones, el cumplimiento y observancia de los principios generales que rigen la función 
pública de acuerdo con lo establecido en esta Constitución y en toda legislación aplicable.

El ejercicio pleno de los derechos consignados en el presente título será garantizado través de los medios de defensa establecidos en el apartado D, del artículo 19 de esta Constitución.

2. La Ciudad de México contará con un sistema para definir, organizar y gestionar la profesionalización y evaluación del servicio de carrera de los entes públicos, así como para establecer esquemas de colaboración y los indicadores que permitan rendir cuentas del cumplimiento de sus objetivos y de los resultados obtenidos. El servicio profesional de carrera aplicará a partir de los niveles intermedios de la estructura administrativa. Solamente los cargos de Secretario, Subsecretario y homólogos serán exentos de la aplicación del servicio profesional de carrera.

Los entes públicos en el ámbito de sus competencias, establecerán políticas de profesionalización y un servicio de carrera fundado en el mérito, la igualdad de oportunidades y la paridad de género. Serán transparentes estarán orientadas a que las personas servidoras públicas observen en su actuar los principios rectores de los derechos humanos y los principios generales que rigen la función pública.

A efecto de garantizar la integralidad del proceso de evaluación, las leyes fijarán los órganos rectores, sujetos y criterios bajo los cuales se organizarán los procesos para el ingreso, capacitación, formación, certificación, desarrollo, permanencia y evaluación del desempeño de las personas servidoras públicas, así como el respeto a sus derechos laborales.

\section{Artículo 61}

De la fiscalización y el control interno en la Ciudad de México

1. Todos los entes públicos de la Ciudad de México contarán con órganos internos de control y tendrán los siguientes objetivos:

I. Prevenir, corregir e investigar actos u omisiones que pudieran constituir responsabilidades administrativas;

II. Sancionar e imponer las obligaciones resarcitorias distintas a las que son competencia del Tribunal de Justicia Administrativa de la Ciudad de México; así como sustanciar las responsabilidades relativas a faltas administrativas graves, turnándolas al Tribunal de Justicia Administrativa para su resolución

III. Revisar y auditar el ingreso, egreso, manejo, custodia y aplicación de recursos públicos así como de los recursos privados provenientes de la prestación de un

Esta obra está bajo una Licencia Creative Commons

Atribución-NoComercial-SinDerivar 4.0 Internacional, IIJ-UNAM.

Boletín Mexicano de Derecho Comparado, núm. 152, pp. 869-912. 
servicio público o al amparo de contratos u otras relaciones jurídicas con el gobierno de la Ciudad de México, con especial atención a los contratos de obra pública, servicios, adquisiciones y la subrogación de funciones de los entes públicos en particulares, incluyendo sus términos contractuales y estableciendo un programa de auditorías especiales en los procesos electorales;

IV. Presentar ante la fiscalía que corresponda, las denuncias por hechos $\mathrm{u}$ omisiones que puedan ser constitutivos de delito aportando los datos de prueba que las sustenten;

V. Recibir, dar curso e informar el trámite recaído a las denuncias presentadas por ciudadanos o por las Contralorías Ciudadanas, y

VI. Recurrir las determinaciones de la fiscalía y del Tribunal de Justicia Administrativa, siempre que contravengan el interés público, en los términos que disponga la Ley.

2. Los órganos internos de control serán independientes de las dependencias a las que se les asignen y su titularidad será ocupada de manera rotativa. Las personas titulares de los órganos internos de control serán seleccionados y formados a través de un sistema de profesionalización y rendirán cuentas ante el Sistema Local Anticorrupción. La Ley establecerá las facultades e integración de dichos órganos.

3. La secretaría encargada del control interno será la dependencia responsable de prevenir, investigar y sancionar las faltas administrativas en el ámbito de la administración pública, su titular será designado por las dos terceras partes de los miembros presentes en sesión del Congreso de la Ciudad de México a propuesta en terna del Jefe de Gobierno y podrá ser removido por éste de conformidad con las causas establecidas en la ley, el Congreso de la Ciudad de México podrá objetar dicha determinación por las dos terceras partes de sus miembros presentes. Contará con un área de contralores ciudadanos que realizaran sus funciones de forma honorifica, por lo que no percibirán remuneración alguna; serán nombrados junto con el órgano interno de control y coadyuvarán en los procesos de fiscalización gozando de la facultad de impugnar las resoluciones suscritas por los contralores internos que afecten el interés público.

4. La ley establecerá el procedimiento para determinar la suspensión, remoción y sanciones de los titulares de los órganos internos de control que incurran en responsabilidades administrativas o hechos de corrupción.

5. Cualquier ciudadano podrá denunciar hechos de corrupción y recurrir las resoluciones del órgano interno de control de conformidad con los requisitos que al efecto establezca la Ley de la materia. 


\section{Artículo 62}

\section{Del Sistema de Fiscalización Superior}

1. La entidad de fiscalización de la Ciudad de México tendrá plena autonomía constitucional, de gestión, técnica y presupuestal. Será independiente en sus decisiones y profesional en su funcionamiento. en el ejercicio de sus funciones, para decidir sobre su organización interna, funcionamiento y resoluciones. Ejercerá sus funciones de fiscalización y evaluación bajo los principios de legalidad, imparcialidad, confiabilidad, eficacia y eficiencia, adoptando para tal efecto las mejores prácticas.

2. La Entidad de fiscalización iniciará los procesos ordinarios de fiscalización a partir del primer día hábil del ejercicio fiscal siguiente, con excepción de lo establecido en la fracción I, del numeral 7 del presente artículo y sin perjuicio de que las observaciones o recomendaciones que, en su caso realice, deberán referirse a la información definitiva presentada en la cuenta pública. La fiscalización de la Cuenta Pública comprende la gestión financiera y al desempeño para verificar el grado de cumplimiento de los objetivos de los entes públicos, siendo ambos resultados vinculatorios en materia de responsabilidades de servidores públicos.

Sin demerito de lo anterior, la entidad de fiscalización de la Ciudad de México podrá llevar a cabo, conforme a la ley de la materia, fiscalizaciones, observaciones, auditorías parciales, en todo momento, a toda acción u obra de la administración que utilice recursos públicos de la ciudad y podrá solicitar información del ejercicio en curso, respecto de procesos concluidos.

En el ejercicio de su función fiscalizadora no le serán oponibles las disposiciones dirigidas a proteger la secrecía de la información en materia fiscal o la relacionada con operaciones de depósito, administración, ahorro e inversión de recursos monetarios. La ley establecerá los procedimientos para que les sea entregada dicha información.

3. Dicha entidad deberá fiscalizar las acciones del gobierno de la Ciudad de México y de las Alcaldías en materia de fondos, recursos patrimoniales, así como contratación, uso y destino de la deuda pública. Los informes de auditoría tendrán carácter público y deberán cumplir con estándares de datos abiertos. La entidad de referencia fiscalizará y auditará el manejo, custodia y aplicación de los recursos públicos que se asignen al Poder Judicial, a la legislatura de la Ciudad de México, así como a cualquier órgano o ente público de la ciudad.

4. La Jefatura de Gobierno deberá enviar la cuenta pública de cada ejercicio fiscal a más tardar el 30 de abril del año inmediato posterior.

5. El titular de la entidad de fiscalización de la Ciudad de México será nombrado por la legislatura de la Ciudad, por el voto de dos terceras partes

Esta obra está bajo una Licencia Creative Commons

Atribución-NoComercial-SinDerivar 4.0 Internacional, IIJ-UNAM.

Boletín Mexicano de Derecho Comparado, núm. 152, pp. 869-912. 
de los presentes, a partir de una convocatoria pública abierta. El ente fiscalizador atenderá de manera obligatoria las áreas de desempeño, financiera, forense, jurídica, de gestión y cualquier otra que considere necesaria.

6. Los candidatos a ser integrantes de la directiva de la Entidad de fiscalización de la Ciudad de México deberán cumplir con los siguientes requisitos:

I. Contar con una experiencia mínima de cinco años en materias de control, auditoría financiera y de responsabilidades administrativas;

II. Ser ciudadano mexicano y estar en pleno goce de sus derechos civiles y políticos;

III. Gozar de buena reputación y no haber sido condenado por delito doloso;

IV. Haber residido en la Ciudad de México durante los dos años anteriores al día de la designación;

V. No haber sido titular de una secretaria ni legislador federal o de las entidades federativas, ni haber sido titular de una alcaldía o municipio en los tres años previos al inicio del proceso de examinación, y

VI. Los demás requisitos que señale la ley.

7. La Entidad de fiscalización de la Ciudad de México tendrá a su cargo:

I. Fiscalizar en forma posterior o mediando denuncia específica, en cualquier momento:

a) Los ingresos, egresos y deuda de la Ciudad de México, y

b) El manejo, la custodia y la aplicación de fondos y recursos de los entes públicos de la ciudad;

II. Realizar auditorías sobre el desempeño en el cumplimiento de los objetivos contenidos en los programas de la Ciudad de México, a través de los informes que se rendirán en los términos que disponga la ley;

III. Coadyuvar con la Auditoría Superior de la Federación para la adecuada y eficiente realización de sus facultades de fiscalización de recursos federales en la ciudad;

IV. Fiscalizar los recursos locales que se destinen y se ejerzan por cualquier entidad, persona física o moral, pública o privada, y los transferidos a fideicomisos, fondos y mandatos, públicos o privados, o cualquier otra figura jurídica así como de los recursos privados provenientes de la prestación de un servicio público o al amparo de contratos u otras relaciones jurídicas con el gobierno de la Ciudad de México, de conformidad con los procedimientos establecidos en las leyes y sin perjuicio de la competencia de otras autoridades de los derechos de los usuarios del sistema financiero;

V. Auditar la estricta observancia de la ley, así como señalar cualquier riesgo de conflicto de interés o de utilización de recursos o compromisos generados para campañas electorales, en la asignación por cualquier medio jurídico y en cualquiera de 
sus etapas, de obra pública, de obra asociada a proyectos de infraestructura, de servicios públicos, de adquisiciones o de subrogación de funciones y obligaciones que involucren a algún ente público, y los compromisos plurianuales de gasto que puedan derivar de éstos;

VI. Solicitar y revisar información de ejercicios anteriores al de la cuenta pública en revisión, sin que por este motivo se entienda, para todos los efectos legales, abierta nuevamente la cuenta pública del ejercicio al que pertenece la información solicitada; exclusivamente cuando el programa, proyecto o la erogación contenidos en el presupuesto en revisión abarque diversos ejercicios fiscales o se trate de revisiones sobre el cumplimiento de los objetivos en las aplicaciones de los recursos de la Ciudad de los entes públicos y cualquier otra institución de carácter público o privado que aplique, maneje o aplique recursos públicos. Las observaciones y recomendaciones que emita la Entidad de fiscalización se referirán al ejercicio de los recursos públicos de la cuenta pública en revisión.

VII. Sin perjuicio de lo anterior, en las situaciones que determine la Ley derivado de denuncias, la entidad de fiscalización, revisará el ejercicio fiscal en curso o anteriores de las entidades fiscalizadas. La Entidad de fiscalización de la Ciudad de México rendirá un informe específico al congreso local y promoverá las acciones que correspondan ante el Tribunal de Justicia Administrativa de la Ciudad de México, la Fiscalía Especializada en Combate a la Corrupción o las autoridades competentes;

VIII. Las entidades fiscalizadas proporcionarán la información que se solicite para la revisión, en los plazos y términos señalados por la ley y en caso de incumplimiento, serán aplicables las sanciones previstas en la misma.

IX. Entregar al Congreso de la ciudad, el último día hábil de los meses de junio y octubre, así como el 20 de febrero del año siguiente al de la presentación de la cuenta pública, los informes individuales de auditoría que concluya durante el periodo respectivo. Asimismo, en esta última fecha, entregar el Informe General Ejecutivo del Resultado de la Fiscalización Superior de la Cuenta Pública, el cual se someterá a la consideración del pleno del Congreso local. El Informe General Ejecutivo y los informes individuales serán de carácter público en formato de datos abiertos y tendrán el contenido que determine la ley; estos últimos incluirán como mínimo el dictamen de su revisión, un apartado específico con las observaciones de la Entidad de fiscalización de la Ciudad de México, así como el informe justificado y las aclaraciones que, las entidades fiscalizadas hayan presentado sobre las mismas;

$\mathrm{X}$. Investigar los actos u omisiones que impliquen alguna irregularidad o conducta ilícita en el ingreso, egreso, manejo, custodia, aplicación, asignación, transferencia y licitación de fondos y recursos públicos y efectuar 
visitas domiciliarias únicamente para exigir la exhibición de libros, papeles o archivos indispensables para la realización de sus investigaciones. Así mismo podrá ordenar comparecencias y citaciones a servidores públicos y particulares, salvaguardando los principios del debido proceso;

XI. Investigar y substanciar, dentro del ámbito de su competencia, el procedimiento correspondiente, promover las responsabilidades ante el Tribunal de Justicia Administrativa de la Ciudad de México y la Fiscalía Especializada en Combate a la Corrupción. El Poder Ejecutivo local aplicará el procedimiento administrativo de ejecución para el cobro de las indemnizaciones y sanciones pecuniarias de conformidad con la Ley de la materia, y

XII. Investigar, substanciar e informar de la comisión de faltas administrativas y presentar las denuncias ante las autoridades responsables de ejercer la acción penal, aportando los datos de prueba que la sustenten.

8. Los entes públicos fiscalizados deberán llevar el control y registro contable, patrimonial y presupuestario de los recursos de la Ciudad de México que les sean transferidos y asignados, de acuerdo con los criterios que establezca la ley.

9. El procedimiento del Informe General Ejecutivo del Resultado de la Fiscalización Superior de la Cuenta Pública y de los informes individuales, será el siguiente:

I. De manera previa a la presentación del Informe General Ejecutivo y de los informes individuales de auditoría, se darán a conocer a las entidades fiscalizadas la parte que les corresponda de los resultados de su revisión, a efecto de que éstas presenten las justificaciones y aclaraciones que correspondan, las cuales deberán ser valoradas por la Entidad de fiscalización de la Ciudad de México para la elaboración de los informes individuales de auditoría;

II. La persona titular de la Entidad de fiscalización de la Ciudad de México enviará a las entidades fiscalizadas los informes individuales que les correspondan, a más tardar a los 10 días hábiles posteriores a que haya sido entregado el informe individual de auditoría respectivo al Congreso local, mismos que contendrán recomendaciones y acciones para que, en un plazo de hasta 30 días hábiles, presenten la información y realicen las consideraciones que estimen pertinentes; en caso de no hacerlo se harán acreedores a las sanciones establecidas en ley. Lo anterior no aplicará a las promociones de responsabilidades ante el Tribunal de Justicia Administrativa de la Ciudad de México, las cuales se sujetarán a los procedimientos y términos que establezca la ley;

III. La entidad de fiscalización de la Ciudad de México deberá pronunciarse en un plazo de 120 días hábiles sobre las respuestas emitidas por las entidades fiscalizadas. En caso de no hacerlo, se estará a lo señalado en la 
ley de la materia; la respuesta se tomará como rechazada por la entidad de fiscalización y procederá inmediatamente a tomar y promover las medidas de sanción correspondientes.

IV. La Entidad de fiscalización de la Ciudad de México deberá entregar al Congreso local, los días 1 de los meses de mayo y noviembre de cada año, un informe sobre la situación que guardan las observaciones, recomendaciones y acciones promovidas, correspondientes a cada uno de los informes individuales de auditoría que haya presentado en los términos de este artículo. En dicho informe, el cual tendrá carácter público, la Auditoría incluirá los montos efectivamente resarcidos a la hacienda pública de la ciudad o al patrimonio de los entes públicos locales, como consecuencia de sus acciones de fiscalización, las denuncias penales presentadas y los procesos iniciados ante el Tribunal de Justicia Administrativa de la Ciudad de México; y

V. La Entidad de fiscalización de la Ciudad de México deberá guardar reserva de sus actuaciones y observaciones hasta que rinda los informes individuales de auditoría y el Informe General Ejecutivo al Congreso local; la ley establecerá las sanciones aplicables a quienes infrinjan esta disposición.

\section{Artículo 63}

\section{Del Sistema Anticorrupción de la Ciudad de México}

1. La Ciudad de México contará con un Sistema Anticorrupción que funcionara como un cuarto poder ciudadano de acción permanente orientado a prevenir, investigar y sancionar actos de corrupción en todos los niveles de gobierno. Para el combate a la corrupción este cuarto poder ciudadano se apegará en todo momento a los principios establecidos en la Constitución Política de los Estados Unidos Mexicanos, los tratados y convenciones internacionales en la materia, suscritos por el Estado Mexicano, y la Constitución Política de la Ciudad de México.

2. El Sistema Anticorrupción de la Ciudad de México será instituido a través de un Consejo de Honestidad, Participación Ciudadana, Austeridad y Control Social Este Consejo será ciudadano, tendrá personalidad jurídica, y autonomía administrativa, presupuestaria y organizativa.

A) Los miembros del Consejo de Honestidad, Austeridad y Control Social deberán ser siete ciudadanos imparciales, elegidos por vía del voto universal, directo y secreto cada siete años sin posibilidad de reelección y ejercerán sus funciones con independencia, de conformidad con la ley que regirá este cuarto poder ciudadano anticorrupción de acción permanente.

3. Las atribuciones constitucionales del Consejo de Honestidad, Austeridad, Participación Ciudadana y Control Social serán entre otras:

Esta obra está bajo una Licencia Creative Commons

Atribución-NoComercial-SinDerivar 4.0 Internacional, IIJ-UNAM.

Boletín Mexicano de Derecho Comparado, núm. 152, pp. 869-912. 
A. Implementar mecanismos de participación ciudadana en todas las áreas del gobierno que incluyan entre otros presupuestos participativos, auditorias ciudadanas, plebiscitos, referéndums y todo tipo de instrumentos abiertos de acceso a la justicia.

B. Contar con amplias facultades para investigar y litigar casos de corrupción, pudiendo actuar como parte procesal en las causas que se instauren como consecuencia de sus investigaciones.

C. Proponer leyes y normas orientadas a la protección plena de las garantías laborales, políticas y cívicas de quienes denuncien actos de corrupción en el servicio público, el sector social y las empresas privadas.

D. Seleccionar y designar a los titulares de los organismos especializados de la Ciudad de México, en materias de rendición de cuentas, electoral, judicial y de derechos humanos, incluyendo la Procuraduría General de la Ciudad de México, los ministerios públicos especializados y del fuero común, la Comisión de Derechos Humanos de la Ciudad de México, el Instituto Electoral de la Ciudad de México, el Instituto de Acceso a la Información y Transparencia de la Ciudad de México y la Contraloría Mayor de Hacienda de la Ciudad de México.

E. Coordinar el Sistema Universal de Declaración Patrimonial y Declaraciones Juradas.

F. Supervisar el cumplimiento de la Ley de Austeridady Gasto Eficiente para el Gobierno de la Ciudad de México y los Programa de Austeridad Republicana y en caso contrario aplicar las sanciones legales que correspondan.

G. Solicitar a cualquier entidad o funcionario público o privado la información que considere pertinente para sus investigaciones. Aquellas personas e instituciones que no colaboren con el Consejo y se nieguen a entregar la información solicitada serán sancionados de acuerdo con la ley.

H. Establecer indicadores públicos de desempeño, seguimiento y evaluación.

4. El Consejo de Honestidad, Austeridad, Participación Ciudadana y Control Social será el garante del libre acceso al Sistema Universal de Declaración Patrimonial y Declaraciones Furadas.

5. El Consejo de Honestidad, Austeridad, Participación Ciudadana y Control Social estará a cargo de vigilar la observancia de la probidad, rectitud, y la austeridad republicana. Para ello quedan prohibidos:

A. Los sueldos elevados o excesivos. Ningún funcionario recibirá salarios mayores a los estipulados en la Ley de Austeridad y Gasto Eficiente para el Gobierno de la Ciudad de México y los Programa de Austeridad Republicana.

B. Los bonos y percepciones extraordinarias que representan gastos superfluos para el gobierno.

C. La contratación de servicios médicos privados, seguros de separación individualizado y cajas de ahorro especial para los altos mandos del gobierno, órganos constitucionales autónomos y altas burocracias de partidos políticos y sindicatos. 
D. El otorgamiento de pensiones extraordinarias a las establecidas en la Ley de Seguridad Social.

E. Contratación de aeronaves privadas. Todos los servidores públicos sin excepción utilizarán vuelos comerciales.

F. La contratación abusiva de viajes oficiales al extranjero, servicios de asesoría, de telefonía, de viáticos, informáticos, entre otros.

\section{Artículo 64}

De las responsabilidades administrativas

1. Las personas servidoras públicas serán responsables por las faltas administrativas en que incurran, en los términos previstos en las leyes generales y locales de la materia.

Para efectos del presente título y de la determinación e imposición de responsabilidades, se reputarán servidores públicos de la Ciudad de México, el Jefe de Gobierno, los diputados del Congreso local, los Magistrados del Tribunal Superior de Justicia, los miembros del Consejo de la Judicatura , los integrantes de las Alcaldías, los miembros de los organismos autónomos y en general toda persona que desempeñe un empleo, cargo, función, mandato o comisión de cualquier naturaleza ante éstos; así como las personas físicas y morales que ejerzan actos de autoridad o contraten con entes públicos la ejecución de obra o servicios públicos, de adquisiciones, de subrogación de funciones o reciban concesiones.

2. Toda persona servidora pública tendrá la obligación de presentar y comprobar de manera oportuna y veraz las declaraciones sobre su situación patrimonial, el cumplimiento de sus obligaciones fiscales y sus posibles conflictos de interés, que serán publicitadas en los términos que determinen las leyes generales y locales respectivas bajo los principios de transparencia, máxima publicidad y protección de datos.

3. Los particulares que incurran en faltas administrativas graves serán sancionadas con inhabilitación para participar en adquisiciones, arrendamientos, prestación de servicios y contratación de obras pública y para desempeñar empleos públicos; el resarcimiento de los daños y perjuicios ocasionados, con independencia de cualquier otra responsabilidad en la que incurran, en los términos que establezca la ley.

4. Las personas morales serán sancionadas en los términos señalados en el párrafo anterior, cuando las faltas administrativas sean cometidos por personas físicas que actúen en nombre o representación de la persona moral y en beneficio de ella. Cuando se acredite que dichos actos causaron un perjuicio 
a la hacienda pública o a los entes públicos de la ciudad, también podrá ordenarse, por autoridad judicial competente, la suspensión de actividades o la disolución o intervención de la sociedad respectiva, siempre que la persona moral haya obtenido un beneficio económico y se acredite participación de sus órganos de administración, de vigilancia o de sus socios, o en aquellos casos en que se advierta que la persona moral es utilizada de manera sistemática para vincularse con faltas administrativas graves; en estos supuestos la sanción se ejecutará hasta que la resolución sea definitiva.

5. La ley señalará los casos de prescripción de la responsabilidad administrativa. No habrá prescripción cuando los actos u omisiones fuesen graves $\underline{\text { los }}$ plazos de prescripción no serán inferiores a siete años.

6. La Ley determinará los casos en los que se incurra en conflicto de intereses y establecerá las sanciones en la materia que corresponda. Definirá las responsabilidades en que incurran las personas servidoras públicas y en su caso los particulares, personas físicas o morales que no manifiesten y se beneficien económica o políticamente de la existencia de dichos conflictos.

6. El Congreso local establecerá una Ley para tipificar y sancionar los casos de conflicto de interés, establecer restricciones a las actividades profesionales de las personas servidoras públicas una vez que se separen de sus cargos, definir los procedimientos para la consulta pública de la identidad de las personas fisicas y morales involucradas en el establecimiento $y$ gestión de empresas que prestan un servicio público o generan ganancias al amparo de contratos u otras relaciones jurídicas con el gobierno de la Ciudad de México, así como ordenar la declaración jurada de los servidores públicos sobre sus actividades externas, empleos, inversiones, activos, regalos o beneficios importantes que puedan dar lugar a un conflicto de intereses respecto de sus atribuciones como funcionarios públicos. También deberá regular las responsabilidades administrativas en que incurran los particulares por el financiamiento ilícito a campañas electorales. La promoción de personas fisicas o agrupaciones políticas mediante el uso de recursos públicos o recursos privados generados al amparo de contratos u otras relaciones jurídicas con el gobierno de la Ciudad de México tendrá como consecuencia la inhabilitación y las sanciones que determine la legislación penal. Entre las sanciones que se establezcan en la Ley a que se refiere este párrafo, se incluirá la nulidad o revocación de los contratos que se hayan celebrado con entes públicos y las demás que resulten procedentes.

7. La ley regulará las responsabilidades correspondientes a las relaciones contractuales multianuales entre los sectores público, social, privado y organizaciones ciudadanas para mejorar el bienestar social y la gestión urbana, asegurando audiencias y máxima publicidad.

7. Se prohíben las asociaciones público-privadas en la Ciudad de México. 


\section{Artículo 66}

De la responsabilidad penal

1. Las personas servidoras públicas son responsables por los delitos que cometan durante el tiempo de su encargo. Ninguna goza de fuero o inmunidad.

2. Los diputados al Congreso de la Ciudad de México son inviolables sus opiniones que manifiesten en el desempeño de sus cargos, y jamás podrán ser reconvenidos por ellas. Su presidente velará por el respeto la inviolabilidad del recinto donde se reúnan a sesionar.

3. La Ley determinará el procedimiento para el ejercicio de la acción penal tratándose de delitos del fuero común, observándose lo establecido en el artículo 19 de la Constitución Política de los Estados Unidos Mexicanos.

4. El plazo de prescripción de Los delitos cometidos por servidores públicos, incluyendo cohecho, peculado, enriquecimiento ilícito, tráfico de influencias o cualquier otro que implique malversación de recursos o deuda públicos no prescribirán, y cualquier plazo existente se interrumpirá cuando el presunto responsable haya eludido la acción de la justicia. 